\title{
Design of Novel BELBIC Controlled Semi-Active Suspension and Comparative Analysis with Passive and PID Controlled Suspension
}

\author{
Pankaj SHARMA* and Vinod KUMAR \\ Department of Mechanical Engineering, National Institute of Technology, Kurukshetra, India
}

\author{
("Corresponding author’s e-mail: ppankaj.ps@gmail.com)
}

Received: 26 September 2019, Revised: 13 February 2020, Accepted: 26 March 2020

\begin{abstract}
Passenger comfort, quality of ride, and handling have broughta lot of attention and concern toautomotive design engineers. These 2 parameters must have optimum balance as they have an inverse effect on each other. Researchers have proposed several approaches and techniques like PID control, fuzzy approach, GA, techniques with inspiration from nature and hybrid techniques to attain the same. A new controller based on the learning behavior of the human brain has been used for the control of semiactive suspension in this study. The controller is known as the Brain Emotional Learning-Based Intelligent Controller (BELBIC). A one-fourth model of car along with the driver model having 6 degrees of freedom (DOF) wasmodeled and simulated. The objective of the studywasto analyze the performance of the proposed controller for improving the dynamic response of the vehicle model coupled with complex biodynamic models of the human body as a passenger, making the whole dynamic system very complex to control. The performance wasanalyzed based on percentage reduction in the overshoot of the vehicle's sprung mass as well as different human body parts when subjected to road disturbances. The proposed controller performance wascompared with the PID controller, widely used in semi-active suspension. The simulation results obtained for BELBIC controlled system for circular road bump showed that the overshoot of passenger head and body wasreduced by 18.84 and $18.82 \%$, respectively and reduction for buttock and leg displacement was18.87\%. The vehicle's seat and sprung mass displacement displayedan improvement of 18.90 and $18.51 \%$. The overshoot of passenger's head and body displacement wasimproved by 19.79and $19.62 \%$, respectively, whereas improvement for buttock \& leg, vehicle's seat, and sprung mass displacement were19.81, 20.00, and $20.49 \%$ against trapezoidal speed bump. The PID controlled suspension disclosed an improvement of 8.74, 8.53, 8.75, 11.11, 14.75 $\%$ against circular bump and 10.72, 10.33, 10.73, 11.11 and $11.75 \%$ against trapezoidal bump for overshoot reduction of passenger head, body, buttock \& leg, vehicle's seat and sprung mass displacement, respectively. The proposed BELBIC controlled semi-active suspension outperformed the widely used PID controlled semi-active suspension and indicated asignificant improvement in the ride quality of the vehicle.
\end{abstract}

Keywords: BELBIC, Emotional learning, Hybrid, PID, Semi-active 
http://wjst.wu.ac.th

\section{Nomenclature}

\begin{tabular}{|c|c|c|}
\hline Symbol & Description & Unit \\
\hline $\mathrm{F}_{\mathrm{MR}}$ & Damping force & $\mathrm{N}$ \\
\hline $\mathrm{K}_{1}$ & Accumulator stiffness & $\mathrm{Nm}^{-1}$ \\
\hline $\mathrm{K}_{0}$ & Spring stiffness & $\mathrm{Nm}^{-1}$ \\
\hline $\mathrm{X}_{0}$ & Initial displacement & $\mathrm{m}$ \\
\hline$\gamma, \beta$ & Scale and shape of the hysteresis loop & $\mathrm{m}^{-2}$ \\
\hline $\mathrm{A}, \mathrm{n}$ & Scale and shape of the hysteresis loop & constant \\
\hline A & Scaling value for the Bouc-Wen model & $\mathrm{Nm}^{-1}$ \\
\hline $\mathrm{H}$ & Time constant & $\mathrm{s}^{-1}$ \\
\hline$i$ & Current from controller & A \\
\hline$x$ & Displacement & $\mathrm{m}$ \\
\hline$x$ & Velocity & $\mathrm{ms}^{-1}$ \\
\hline $\mathrm{Y}$ & Internal displacement & $\mathrm{m}$ \\
\hline $\mathrm{C}_{1}$ & Viscous damping at low velocity & $\mathrm{Nsm}^{-1}$ \\
\hline $\mathrm{C}_{0}$ & Viscous damping at large velocity & $\mathrm{Nsm}^{-1}$ \\
\hline $\mathrm{M}_{\mathrm{SR}}$ & Sprung Mass & $\mathrm{Kg}$ \\
\hline $\mathrm{M}_{\mathrm{US}}$ & Unsprung Mass & $\mathrm{Kg}$ \\
\hline $\mathrm{M}_{\mathrm{BL}}$ & Mass Buttock \& Legs & $\mathrm{Kg}$ \\
\hline $\mathrm{M}_{\mathrm{HE}}$ & Head Mass & $\mathrm{Kg}$ \\
\hline $\mathrm{M}_{\mathrm{BO}}$ & Body Mass & $\mathrm{Kg}$ \\
\hline $\mathrm{M}_{\mathrm{SE}}$ & Seat Mass & $\mathrm{Kg}$ \\
\hline $\mathrm{K}_{\mathrm{TR}}$ & Tire Stiffness & $\mathrm{N} / \mathrm{m}$ \\
\hline $\mathrm{K}_{\mathrm{SR}}$ & Suspension Spring Stiffness & $\mathrm{N} / \mathrm{m}$ \\
\hline $\mathrm{K}_{\mathrm{BL}}$ & Buttock \& Legs Stiffness & $\mathrm{N} / \mathrm{m}$ \\
\hline $\mathrm{K}_{\mathrm{HE}}$ & Head Stiffness & $\mathrm{N} / \mathrm{m}$ \\
\hline $\mathrm{K}_{\mathrm{BO}}$ & Body Stiffness & $\mathrm{N} / \mathrm{m}$ \\
\hline $\mathrm{K}_{\mathrm{SE}}$ & Seat Stiffness & $\mathrm{N} / \mathrm{m}$ \\
\hline $\mathrm{C}_{\mathrm{SR}}$ & Suspension Damping & $\mathrm{N}-\mathrm{s} / \mathrm{m}$ \\
\hline $\mathrm{C}_{\mathrm{BL}}$ & Buttock \& Legs Damping & $\mathrm{N}-\mathrm{s} / \mathrm{m}$ \\
\hline $\mathrm{C}_{\mathrm{HE}}$ & Head Damping & $\mathrm{N}-\mathrm{s} / \mathrm{m}$ \\
\hline $\mathrm{C}_{\mathrm{SE}}$ & Seat Damping & $\mathrm{N}-\mathrm{s} / \mathrm{m}$ \\
\hline $\mathrm{C}_{\mathrm{BO}}$ & Body Damping & $\mathrm{N}-\mathrm{s} / \mathrm{m}$ \\
\hline $\mathrm{W}_{\mathrm{RD}}$ & Bump Height & $\mathrm{cm}$ \\
\hline $\mathrm{X}_{\mathrm{SR}}, \mathrm{X}_{\mathrm{US}}, \mathrm{X}_{\mathrm{BL}}, \mathrm{X}_{\mathrm{HE}}, \mathrm{X}_{\mathrm{BO}}, \mathrm{X}_{\mathrm{SE}}$ & Displacement & $\mathrm{m}$ \\
\hline$\dot{\mathrm{X}}_{\mathrm{SR}}, \dot{\mathrm{X}}_{\mathrm{US}}, \dot{\mathrm{X}}_{\mathrm{BL}}, \dot{\mathrm{X}}_{\mathrm{HE}}, \dot{\mathrm{X}}_{\mathrm{BO}}, \dot{\mathrm{X}}_{\mathrm{SE}}$ & Velocity & $\mathrm{ms}^{-1}$ \\
\hline$\ddot{\mathrm{X}}_{\mathrm{SR}}, \ddot{\mathrm{X}}_{\mathrm{US}}, \ddot{\mathrm{X}}_{\mathrm{BL}}, \ddot{\mathrm{X}}_{\mathrm{HE}}, \ddot{\mathrm{X}}_{\mathrm{BO}}, \ddot{\mathrm{X}}_{\mathrm{SE}}$ & Acceleration & $\mathrm{ms}^{-2}$ \\
\hline $\mathrm{K}_{\mathrm{E} 1}$ & Gain for emotional signal & Constant \\
\hline $\mathrm{K}_{\mathrm{E} 2}$ & Gain for orbitofrontal cortex & Constant \\
\hline$\alpha_{\text {be }}$ & Learning rate gain amygdala & $\mathrm{m}$ \\
\hline$\beta_{\text {be }}$ & Learning rate gain orbitofrontal cortex & $\mathrm{m}$ \\
\hline
\end{tabular}


http://wjst.wu.ac.th

\section{Introduction}

The design of a good suspension system remains a challenging task for vehicle designers since their introduction. The challenges involved in design are the control of multiple parameters with objectives very complex in nature. It is always a challenge and concern for the vehicle designer to have the best possible balance between quality of vehicle ride and handling, thus maintaining a high standard under different conditions of driving. Suspension needs to perform at its best under conditions like different road profiles, variation in vehicle speed, and changing loads. The vehicle should display good ground holding ability along with comfort to the passenger while passing through bumps, potholes, or roads with a random profile. It should not let the vehicle face oscillations large in amplitude as well as should be capable of setting down the oscillations as quickly as possible. Engineers are coming out with new and advanced techniques and design of the suspension system to overcome this problem. The tremendous advancement in the electronic field has led engineers to develop a suspension system based on the mechatronic approach. The suspension systems thus introduced have different techniques and approaches of control. Bashir et al. [1] proposed a hybrid Fuzzy-PID controller for semi-active suspension. The model used for simulation was 3DOF quarter car model. The tuning of PID gains was done by a fuzzy controller. The response was analyzed against random road profiles and speed bumps in the time domain. The results showed improvement in the performance of the vehicle in terms of reduction in sprung mass acceleration, acceleration of seat, and suspension travel. The proposed controller proved better than the conventional fuzzy controller. Upadhyaya and Gupta [2] analyzed the performance of the PID controller in controlling the semi-active suspension. The control strategy used hybridizing PID with the Hळ controller. The performance was analyzed by simulating a 2-degree freedom car model against the random road profile. The result showed a reduction in the displacement of the vehicle body, thereby increasing the ride comfort. GoutamPohit [3] simulated the semi-active suspension model with a fuzzy controller. The model was simulated for dynamic analysis under different road profiles. The proposed fuzzy controller showed a better response for ride quality by reducing the displacement of the system in comparison to uncontrolled or passive suspension. Keramatet al. [4] proposed an intelligent controller that mimics the learning behavior of a mammal's brain, known as the BELBIC controller. The controller was proposed for controlling the voltage output of the DC-DC converter. They compared the performance of the BELBIC controller with a commonly used fuzzy controlled DC-DC converter. The BELBIC controller outperformed the fuzzy by bringing the overshoots and fluctuation of voltage to a negligible level. Jafariet al. [5] worked on a biologically inspired controller working on the emotional learning phenomena of the human brain, known as the BELBIC controller. They worked on analyzing the performance of the proposed controller on controlling the faults, disturbances of microgrids of power systems. The performance was validated in reference to errors in voltage and frequency for microgrid simulation. The results showed efficient control by the proposed controller in comparison to other commonly used benchmarked controller for microgrids. Vanapalli and Rao [6] proposed an intelligent controller known as the BELBIC controller in Unified Power Quality Conditioner (UPQC) for the control of DC interface voltage. The proposed controller because of its inherent auto-learning quality responded very quickly and effectively for controlling the DC interface voltage under rapidly changing working conditions. Khorashadizadehet al. [7] used the BELBIC controller for error tracking control of a large group of complex and nonlinear systems. They used the proposed controller as an estimator of uncertainty. The simulation of speed control of induction motor by BELBIC controller is done, and performance is compared with the neuro-fuzzy controlled system. The proposed controller overcomes the external disturbance with better tracking of error, therefore proving superiority over the other controlled systems. Ramesh and Yadaiah [8] worked on a bio-inspired controller known as BELBIC for controlling the position of DC motor. The controller's parameter i.e. learning rates and reward signal was tuned using a data-based algorithm for tuning. The proposed system has shown a much better transient response compared to that of the PID controlled system. Cesar et al. [9] worked on the civil structure of a single DOF. The structure was analyzed against the earthquake excitation and results were compared with BELBIC controlled structure. The performance of BELBIC system came out better against earthquake excitation. Youness and Lobusov [10] worked on the simulation of a full car model with 2 different types 
http://wjst.wu.ac.th

of suspension controllers. The simulation was done on one PID controlled system and the other with the LQR controller. The result showed PID controlled system performed better than LQR. The performance was analyzed based on control of suspension travel of the car. Sharma and Kumar [11] proposed the use of BELBIC controller on the quarter vehicle model with a semi-active suspension approach. The model is simple in construction studied the performance of the proposed controller at the preliminary stage of suspension design. The simulation result obtained showed a decrease in overshoot and settling time of BELBIC controlled suspension in comparison to passive suspension, and showed the further scope for the use of this novel controller on a more realistic higher DOF system with a real road bump profile. Dutta and Prakash [12] worked on the use of BELBIC controller for control of load frequency in the hybrid power system of 2 areas. Integration of power system was done with DG sources like biomass and solar. The nonlinear effects and communication delay were considered for making the system more realistic. The results of the proposed system were compared with PID and fraction order PID. The simulation results obtained for BELBIC were better than the other 2 control system for variable parameters and operating load. Sostheneet al. [13] worked on developing a fuzzy logic controller for semi-active suspension. Two degrees of freedom model of vehicle is simulated for performance evaluation of fuzzy controller in improving the ride quality. The results were compared with a passive suspension system. The result showed an improvement of $10 \%$ in ride quality and $30 \%$ for the stability of the vehicle. Lotfi and Rezaee [14] used the controller based on the emotional learning ability of the human brain known as BELBIC to analyze the performance in controlling the motion of the robotic arm and for temperature control of the reactor tank with a continuous stirrer. The result showed that the proposed BELBIC has a good controlling ability. Sahet al. [15] worked on the study of whole-body vibration of the human body when traveling in the vehicle. They prepared a mathematical model of an electric vehicle with a passenger. The simulation is done using the Simulink model and the results obtained were compared with experimental results. The results obtained by simulation and experiments were almost similar, thereby concluding that the proposed model can be used to successfully predict the behavior of the vehicle while moving over the road for designing the suspension. Hong et al. [16] proposed a fusion controller in combination with PID and BELBIC controllers. The proposed controller is used for the position control of a robot. The natural frequencies were obtained by the finite element method and were compared with the experimentally obtained ones. The simulation results were obtained using the Simulink model and the robustness of the proposed controller is identified. Asarryet al. [17] simulated a semi-active suspension model. The model used a hybrid controller Fuzzy-PID controller. The Bingham model was used for the MR damper model. The model was simulated against step input as road disturbance. The result showed a decrease of $87.28 \%$ in acceleration for the system with hybrid control, $79.95 \%$ for PID controlled semiactive suspension. Amiruddinet al. [18] carried out research on the calculation of the control algorithm. The target force generated by the MR damper was investigated with these algorithms. The work was performed on PID controlled MR damper with a spring-mass damper system. The results came out with significant improvement for PID controlled system. Senthilkumaret al. [19] developed a fuzzy controller for monitoring of hardness and tensile strength of nugget in friction stir welding. The fuzzy controller used tools speed, feed, and depth of cut as 3 input parameters and tensile strength and hardness as output. The result showed that the controller was able to control the parameters with an error of $1.31 \%$ only, thereby making it scope to be used in other control problems. Researchers have introduced new techniques of control, which are inspired by the biological behavior of animals, insects, and human beings, etc. under different conditions. Chatlatanagulchai and Benjalersyarnon [20] worked on a quantitative feedback controller for controlling the vibrations induced in 2 staged pendulums. In one technique they placed input shaper outside the closed system. In this case, the controller was able to reduce the vibration generated by the reference input only; the outside disturbances could not be taken care of by the controller. The other technique had a controller placed along with an input shaper. In this case, the controller was able to reduce the vibrations induced by other sources such as noise, disturbances, and uncertainties. Shahriaret al. [21] simulated a passive model of the suspension system. The Simulink model is used for their work and was analyzed for bounce and pitch response of the car. The vehicle was analyzed against the cosine road profile. Priya and Gopalakrishnan [22] worked on the semi-active civil structure. The structure was modeled and simulated with the MR damper. The bouc wen parametric 
http://wjst.wu.ac.th

model of the MR damper was used. The parameters of the damper were identified using curve fitting techniques. The simulated results were analyzed with experimentally obtained values and were found quite satisfactory. Arslan [23] studied the effect of whole-body vibration on the human body. The study was performed using the biodynamic lumped parameter model of a human. The simulation was performed on the vehicle model coupled with the human biodynamic model. The results obtained were compared with experimental work performed for whole-body vibration. Simulation results obtained were good enough to predict the behavior of whole-body vibration. Emam [24] worked on the active suspension system, using a Fuzzy-PID controller. The hybrid approach used a fuzzy controller for tuning the gains of the PID controller, whereas the main control is obtained by PID. They simulated the model of the proposed configuration and compared the results obtained with passive and PID controlled suspension. The results obtained were far better than the passive and PID system in improving the ride quality of the vehicle. Prashantkumaret al. [25] modeled and simulated multiple controllers for the suspension of the vehicle. They studied their effect for different modes of driving as well as for different profiles of the road. Two degrees of freedom model was utilized for simulation work. The controllers studied were PID, Groundhook, and Skyhook controller. Ravi and Mija [26] worked on designing a BELBIC controller for a single DOF spring dashpot system. The system's performance was compared with a single DOF spring dashpot system with a PID controller. The BELBIC controlled system's performance was better than PID controlled. Mihai and Andronic [27] studied the effect of the PID controller in the semi-active suspension system. The suspension was subjected to different types of input and the PID controller was used to control the MR damper. The results were compared with passive suspension. The PID controlled system resulted in a significant decrease in overshoot and settling time of the suspension system, thereby improving the ride quality. Kim and Oh [28] studied the rotary motion of an inverted pendulum system by creating a mathematical model for the same. The motion control was obtained by introducing a new intelligent controller by the name BELBIC. The uncontrolled system's performance was compared with a controlled system, the result proved that BELBIC controlled system is robust and effective in motion control. Metered et al. [29] introduced a new approach to the study of the dynamic behavior of the MR damper. The approach used a 3-dimensional interpolation technique utilizing Chebyshev orthogonal polynomial functions. The approach used finds the force produced by the MR damper. The damping force is a function of velocity, displacement and voltage applied to the damper. The comparative analysis was made between experimental and simulated results. The result showed that the proposed model could predict the damping force with good accuracy. Prasad and Shirahatti[30] analyzed the effect of potholes on 4DOF car model. The simulation result showed that within a specific speed range the ride comfort can be obtained even while the vehicle passes the hump. If the speed is not kept within this range and the hump is crossed, excessive acceleration of the vehicle is observed making the ride very uncomfortable. In the extensive literature survey, it has been found that most of the work carried out with the BELBIC controller is on speed control of electric motors, position control of robotic arms. The researchers have recently studied the effect of the BELBIC controller in stationary civil structure for vibration reduction using anMR damper only. The inspiration for work performed in this paper is due to the fact that semi-active suspension uses springs in combination with MR damper along with moving vehicles, thus making the whole system's response highly nonlinear and complex. The intensive literature survey brings out that not much work has been done for the use of this controller in automotive suspension with a semi-active approach. The work in this paper is carried out to improve the dynamic response in terms of ride quality using a controller with auto-learning ability. The work is carried out on the moving vehicle's suspension model consisting of spring and MR damper coupled with complex biodynamic models of the human body as a passenger, thus making the whole dynamic system very complex to control and interesting area of research. The author has published work on the initial design of 2DOF quarter car model to analyze the feasibility of BELBIC control in semi-active suspension [11]. The results obtained havemotivated this work, in which 6DOF, one-fourth model of car along with passenger is modeled and simulated for a different profile of bumps. In this work an attempt was made to build a more realistic mathematical model of the car coupled with passenger's biodynamic model for the analysis of ride quality and effect of speed bumps on the different body parts of humans, thereby helping in the design of more comfortable suspension system with better dynamic stability. 


\section{Suspension's mathematical formulation}

The automotive suspension system consists of linkages, spring, and damper that connects the vehicle's chassis with its wheel, and also takes care of relative motion between the two. The 2 types of suspension systems considered in this work are passive and semi-active suspension. The passive suspension system consists of a spring and damper commonly known as a shock absorber. The ride quality against the road irregularities is obtained by reducing the relative velocity of the vehicle body and wheel. This is achieved by a viscous fluid-filled damper. The damping properties of the viscous fluid are constant which limits its performance under different profiles of road irregularities. The semi-active suspension consists of a damper filled with a special viscous fluid known as MR fluid. The advantage of this fluid is that its damping properties can be varied when it is subjected to the magnetic field. The performance range of this suspension is increased as the damping rate can be varied according to the road profile. A controller is used in this system that receives a controlling signal whichgenerally is the vertical displacement of the vehicle body and generates an electric signal to produce the magnetic field and resulting in the change of damping produced by the suspension.

The suspension of passive and semi-active configuration along with passenger has been modeled in terms of mathematical expression. The mathematical model is prepared using fundamentals of multi-DOF models of mechanical vibration systems [21]. Two semi-active suspension systems, one based on PID control and others based on the proposed human brain's emotional learning approach known as BELBIC are modeled for analysis through simulation. Figures $\mathbf{1}$ and2 show the arrangement of the proposed quarter car and driver model for passive and semi-active configuration, respectively [15].

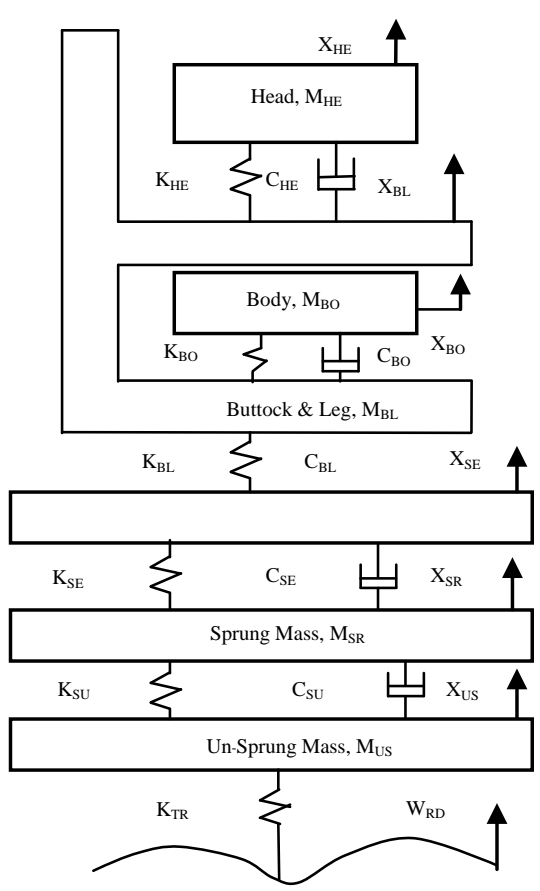

Figure 1 Passive 6DOF $1 / 4^{\text {th }}$ car model.

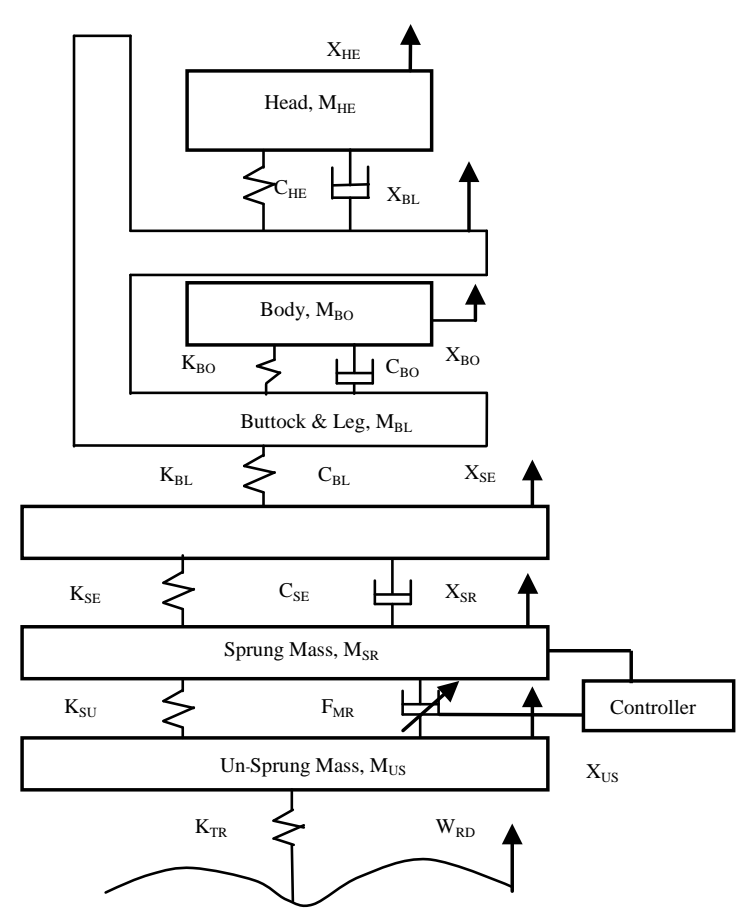

Figure 2 Semi-active $6 \mathrm{DOF} 1 / 4^{\text {th }}$ car model. 
http://wjst.wu.ac.th

The mathematical expression for suspension is modeled along with consideration of vehicle tire, which is modeled as a combination of spring and damper for considering tire's stiffness and damping ability. The equation of motions formulated for vehicle passenger model with passive suspension as per laws of mechanics and the mechanical vibration are given by Eqs. (1) - (6).

$$
\begin{aligned}
& M_{H E} \ddot{\mathrm{X}}_{\mathrm{HE}}-\mathrm{K}_{\mathrm{HE}}\left(\mathrm{X}_{\mathrm{BL}}-X_{H E}\right)-\mathrm{C}_{\mathrm{BO}}\left(\dot{\mathrm{X}}_{\mathrm{BL}}-\dot{\mathrm{X}}_{\mathrm{HE}}\right)=0 \\
& M_{B O} \ddot{\mathrm{X}}_{\mathrm{BO}}-\mathrm{K}_{\mathrm{BO}}\left(\mathrm{X}_{\mathrm{BL}}-X_{B O}\right)-\mathrm{C}_{\mathrm{BO}}\left(\dot{\mathrm{X}}_{\mathrm{BL}}-\dot{\mathrm{X}}_{\mathrm{BO}}\right)=0 \\
& M_{B L} \ddot{\mathrm{X}}_{\mathrm{BL}}+\mathrm{K}_{\mathrm{BO}}\left(\mathrm{X}_{\mathrm{BL}}-X_{B O}\right)-\mathrm{K}_{\mathrm{BL}}\left(\mathrm{X}_{\mathrm{SE}}-X_{B L}\right)-\mathrm{C}_{\mathrm{BL}}\left(\dot{\mathrm{X}}_{\mathrm{SE}}-\dot{X}_{B L}\right)+\mathrm{C}_{\mathrm{BO}}\left(\dot{\mathrm{X}}_{\mathrm{BL}}-\dot{\mathrm{X}}_{\mathrm{BO}}\right)=0 \\
& M_{S E} \ddot{\mathrm{X}}_{\mathrm{Se}}+\mathrm{K}_{\mathrm{SE}}\left(\mathrm{X}_{\mathrm{SE}}-X_{S R}\right)+\mathrm{K}_{\mathrm{BL}}\left(\mathrm{X}_{\mathrm{SE}}-X_{B L}\right)+\mathrm{C}_{\mathrm{BL}}\left(\dot{\mathrm{X}}_{\mathrm{SE}}-\dot{X}_{B L}\right)+\mathrm{C}_{\mathrm{SE}}\left(\dot{\mathrm{X}}_{\mathrm{SE}}-\dot{\mathrm{X}}_{\mathrm{SR}}\right)=0 \\
& M_{S R} \ddot{\mathrm{X}}_{\mathrm{SR}}+\mathrm{K}_{\mathrm{SU}}\left(\mathrm{X}_{\mathrm{SR}}-\mathrm{X}_{\mathrm{US}}\right)+\mathrm{C}_{\mathrm{SU}}\left(\dot{\mathrm{X}}_{\mathrm{SR}}-\dot{\mathrm{X}}_{\mathrm{US}}\right)-\mathrm{K}_{\mathrm{SE}}\left(\mathrm{X}_{\mathrm{SE}}-X_{S}\right)-\mathrm{C}_{\mathrm{SE}}\left(\dot{\mathrm{X}}_{\mathrm{SE}}-\dot{\mathrm{X}}_{\mathrm{S}}\right)=0 \\
& M_{U S} \ddot{\mathrm{X}}_{\mathrm{US}}+\mathrm{K}_{\mathrm{TR}}\left(\mathrm{X}_{\mathrm{US}}-W_{R D}\right)-\mathrm{K}_{\mathrm{SU}}\left(\mathrm{X}_{\mathrm{SR}}-\mathrm{X}_{\mathrm{US}}\right)-\mathrm{C}_{\mathrm{SU}}\left(\dot{\mathrm{X}}_{\mathrm{SR}}-\dot{\mathrm{X}}_{\mathrm{US}}\right)=0
\end{aligned}
$$

Similarly, the equation of motions formulated for vehicle passenger model with semi-active suspension is given by Eqs. (7) - (12) [18].

$$
\begin{aligned}
& M_{H E} \ddot{\mathrm{X}}_{\mathrm{HE}}-\mathrm{K}_{\mathrm{HE}}\left(\mathrm{X}_{\mathrm{BL}}-X_{H E}\right)-\mathrm{C}_{\mathrm{BO}}\left(\dot{\mathrm{X}}_{\mathrm{BL}}-\dot{\mathrm{X}}_{\mathrm{HE}}\right)=0 \\
& M_{B O} \ddot{\mathrm{X}}_{\mathrm{BO}}-\mathrm{K}_{\mathrm{BO}}\left(\mathrm{X}_{\mathrm{BL}}-X_{B O}\right)-\mathrm{C}_{\mathrm{BO}}\left(\dot{\mathrm{X}}_{\mathrm{BL}}-\dot{\mathrm{X}}_{\mathrm{BO}}\right)=0 \\
& M_{B L} \ddot{\mathrm{X}}_{\mathrm{BL}}+\mathrm{K}_{\mathrm{BO}}\left(\mathrm{X}_{\mathrm{BL}}-X_{B O}\right)-\mathrm{K}_{\mathrm{BL}}\left(\mathrm{X}_{\mathrm{SE}}-X_{B L}\right)-\mathrm{C}_{\mathrm{BL}}\left(\dot{\mathrm{X}}_{\mathrm{SE}}-\dot{X}_{B L}\right)+\mathrm{C}_{\mathrm{BO}}\left(\dot{\mathrm{X}}_{\mathrm{BL}}-\dot{\mathrm{X}}_{\mathrm{BO}}\right)=0 \\
& M_{S E} \ddot{\mathrm{X}}_{\mathrm{Se}}+\mathrm{K}_{\mathrm{SE}}\left(\mathrm{X}_{\mathrm{SE}}-X_{S R}\right)+\mathrm{K}_{\mathrm{BL}}\left(\mathrm{X}_{\mathrm{SE}}-X_{B L}\right)+\mathrm{C}_{\mathrm{BL}}\left(\dot{\mathrm{X}}_{\mathrm{SE}}-\dot{X}_{B L}\right)+\mathrm{C}_{\mathrm{SE}}\left(\dot{\mathrm{X}}_{\mathrm{SE}}-\dot{\mathrm{X}}_{\mathrm{SR}}\right)=0 \\
& M_{S R} \ddot{\mathrm{X}}_{\mathrm{SR}}+\mathrm{K}_{\mathrm{SU}}\left(\mathrm{X}_{\mathrm{SR}}-\mathrm{X}_{\mathrm{US}}\right)-\mathrm{K}_{\mathrm{SE}}\left(\mathrm{X}_{\mathrm{SE}}-X_{S}\right)-\mathrm{C}_{\mathrm{SE}}\left(\dot{\mathrm{X}}_{\mathrm{SE}}-\dot{\mathrm{X}}_{\mathrm{S}}\right)+F_{M R}=0 \\
& M_{U S} \ddot{\mathrm{X}}_{\mathrm{US}}+\mathrm{K}_{\mathrm{TR}}\left(\mathrm{X}_{\mathrm{US}}-W_{R D}\right)-\mathrm{K}_{\mathrm{SR}}\left(\mathrm{X}_{\mathrm{SR}}-\mathrm{X}_{\mathrm{US}}\right)-F_{M R}=0
\end{aligned}
$$

\section{MR damper modified bouc wen model}

The semi-active suspension uses a special damper filled with magnetorheological fluid, known as MR damper. The damper when subjected to magnetic field results in a change in the damping properties of MR fluid in real-time. In this work modified bouc wen model is considered for simulating the behavior of the damper. The response of MR damper in terms of force developed and other relative performance parameters are given by Eqs. (13) - (15).

$$
\begin{aligned}
& F_{M R}=\alpha Z+K_{0}(x-y)+C_{0}\left(\dot{x}_{0}-\dot{y}_{0}\right)+K_{1}\left(x-x_{0}\right) \\
& \dot{y}=\frac{1}{\left(C_{1}+C_{0}\right)}\left[\alpha Z+C_{0} \dot{x}+K_{0}(x-y)\right] \\
& Z=-\gamma|\dot{x}-\dot{y}| Z|Z|^{n-1}-\beta(\dot{x}-\dot{y})|Z|^{n}+A(\dot{x}-\dot{y})
\end{aligned}
$$


http://wjst.wu.ac.th

The hysteresis behavior of MR damper varies in response to the current supplied and the parametric relationship of it is given by Eqs. (16) - (18) [22].

$\alpha=\alpha_{a}+\alpha_{b} i$

$C_{0}=C_{0 a}+C_{0 b} i$

$C_{1}=C_{1 a}+C_{1 b} i$

Table 1 gives the parameters of Lord 1005-3 MR damper, which are used for the simulation model in this work and are taken from reference [29].

Table 1 Damper parameter.

\begin{tabular}{ccl}
\hline S.No & Parameter & Value \\
\hline 1. & $\mathrm{~K}_{1}$ & $840 \mathrm{Nm}^{-1}$ \\
2. & $\mathrm{C}_{1 \mathrm{a}}$ & $14649 \mathrm{Nsm}^{-1}$ \\
3. & $\mathrm{C}_{1 \mathrm{~b}}$ & $34622 \mathrm{NsV}^{-1} \mathrm{~m}^{-1}$ \\
4. & $\mathrm{~K}_{0}$ & $3610 \mathrm{Nm}^{-1}$ \\
5. & $\mathrm{C}_{0 \mathrm{a}}$ & $784 \mathrm{Nsm}^{-1}$ \\
6. & $\mathrm{C}_{0 \mathrm{~b}}$ & $1803 \mathrm{NsV}^{-1} \mathrm{~m}^{-1}$ \\
7. & $\mathrm{X}_{0}$ & 0 \\
8. & $\gamma$ & $136320 \mathrm{~m}^{-2}$ \\
9. & $\mathrm{~A}$ & 58 \\
10. & $\beta$ & $2059020 \mathrm{~m}^{-2}$ \\
11. & $\mathrm{n}$ & 2 \\
12. & $\alpha_{\mathrm{a}}$ & $12441 \mathrm{Nm}^{-1}$ \\
13. & $\alpha_{\mathrm{b}}$ & $38430 \mathrm{NsV}^{-1} \mathrm{~m}^{-1}$ \\
14. & $\eta$ & $190 \mathrm{~s}^{-1}$ \\
\hline
\end{tabular}

\section{PID controller}

The proportional-integral-derivative known as PID controller is widely used in industries for closedloop systems. It minimizes the error in the system, which is the difference between the controlled variable and the desired set point. It is a 3-mode controller, in which proportional, integral, and derivative of error is added up to obtain control output. The controller algorithm is given by Eq. (19) [24].

$u(t)=K_{P} e+\left(K_{I} \int_{0}^{t} e d t\right)+K_{D} \frac{d}{d t} e$

where,

Error, e $=$ Set Point-Measured Variable

$\mathrm{K}_{\mathrm{P}}=$ Proportional gain, a tunable parameter

$\mathrm{K}_{\mathrm{I}}=$ Integral gain, a tunable parameter

$\mathrm{K}_{\mathrm{D}}=$ Derivative gain, a tunable parameter

$\mathrm{t}=$ Time

Brain emotional learning-based intelligent BELBIC controller

In this work, an intelligent controller that mimics the emotional learning behavior of the human brain is proposed to control the MR damper of semi-active suspension. The emotions of the human being in response to the surrounding become the input to the brain, which corresponding to the type of emotions 
http://wjst.wu.ac.th

received e.g. happiness, sadness and anger,etc. results in a reaction as output [26]. It receives multiple inputs and gives the single output as an action. This system generates action depending on sensory inputs, resulted from an external source or stimulus, and an internally generated signal known as emotional cue [9]. Amygdala receives the signal from the thalamus and sends it to the orbitofrontal cortex. The difference between the orbitofrontal cortex and amygdala is the output of the limbic system. The complete process of the brain's functioning in the BELBIC controller is expressed as a mathematical relationship by Eqs. (20) - (24) [16].

$\mathrm{A}_{\mathrm{BEL}}=\mathrm{G}_{\mathrm{AD}} \times \mathrm{I}_{\mathrm{SI}}$

$\mathrm{O}_{\mathrm{OC}}=\mathrm{G}_{\mathrm{OC}} \times \mathrm{I}_{\mathrm{SI}}$

$\mathrm{dG}_{\mathrm{AD}} / \mathrm{dt}=$ alpha $\times \mathrm{I}_{\mathrm{SI}} \times \max \left(\mathrm{I}_{\mathrm{ES}}-\mathrm{A}_{\mathrm{BEL}}, 0\right)$

$\mathrm{dG}_{\mathrm{OC}} / \mathrm{dt}=$ beta $\times \operatorname{SI}\left(\mathrm{A}_{\mathrm{BEL}}-\mathrm{O}_{\mathrm{OC}}-\mathrm{I}_{\mathrm{ES}}\right)$

$\mathrm{O}_{\text {Model }}=\left(\mathrm{A}_{\mathrm{BEL}}-\mathrm{O}_{\mathrm{OC}}\right)$

In the expression sensory input, the orbitofrontal cortex and model's output arerepresented as $\mathrm{I}_{\mathrm{SI}}$ $\mathrm{O}_{\mathrm{OC}}$, and $\mathrm{O}_{\text {Model }}$, respectively. The gains for the amygdala and orbitofrontal cortex are given as $\mathrm{G}_{\mathrm{AD}}$ and $\mathrm{G}_{\mathrm{OC}}$, respectively. The structure of the BELBIC controller based on the above relationship is shown in Figure 3.

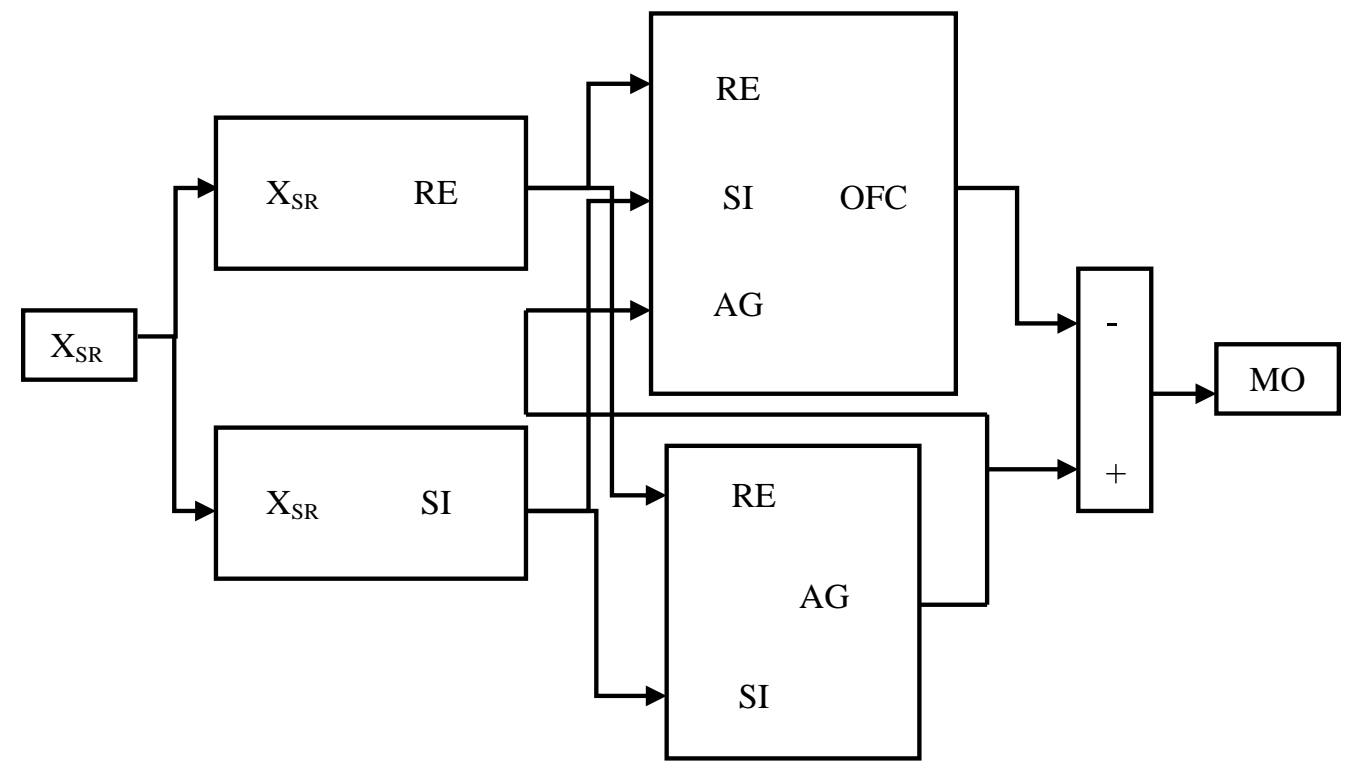

Figure 3 BELBIC controller structure.

Alpha and beta represent the rates of learning for the system. The value assigned to them is generally kept equal; otherwise, amygdala’s learning rate is always assigned with a higher value [28]. 


\section{Simulink model of passive, PID, and BELBIC controlled suspension}

The passive suspension system consists of a spring and damper unit which connects the vehicle's body with the tire. The undulation of the roads gets transferred from tire to vehicle body through suspension. In passive suspension the damper or shock absorber used has a constant damping coefficient, therefore has limited capacity to absorb the shocks resulted due to different road profiles, speed bumps, and potholes. The passive suspension system is an open-loop system where no feedback of the vehicle's response, such as displacement or acceleration of the sprung mass is fed back to the system. The Simulink model of the passive suspension is shown in Figure 4. The Simulink structure shows interlinking of sprung and unsprung mass based on Eqs. (5) and (6). The complete model is not shown here as it will be difficult to bring it on a single page due to its large structure; the complete model can be prepared similarly by interlinking Eqs. (1) - (6).

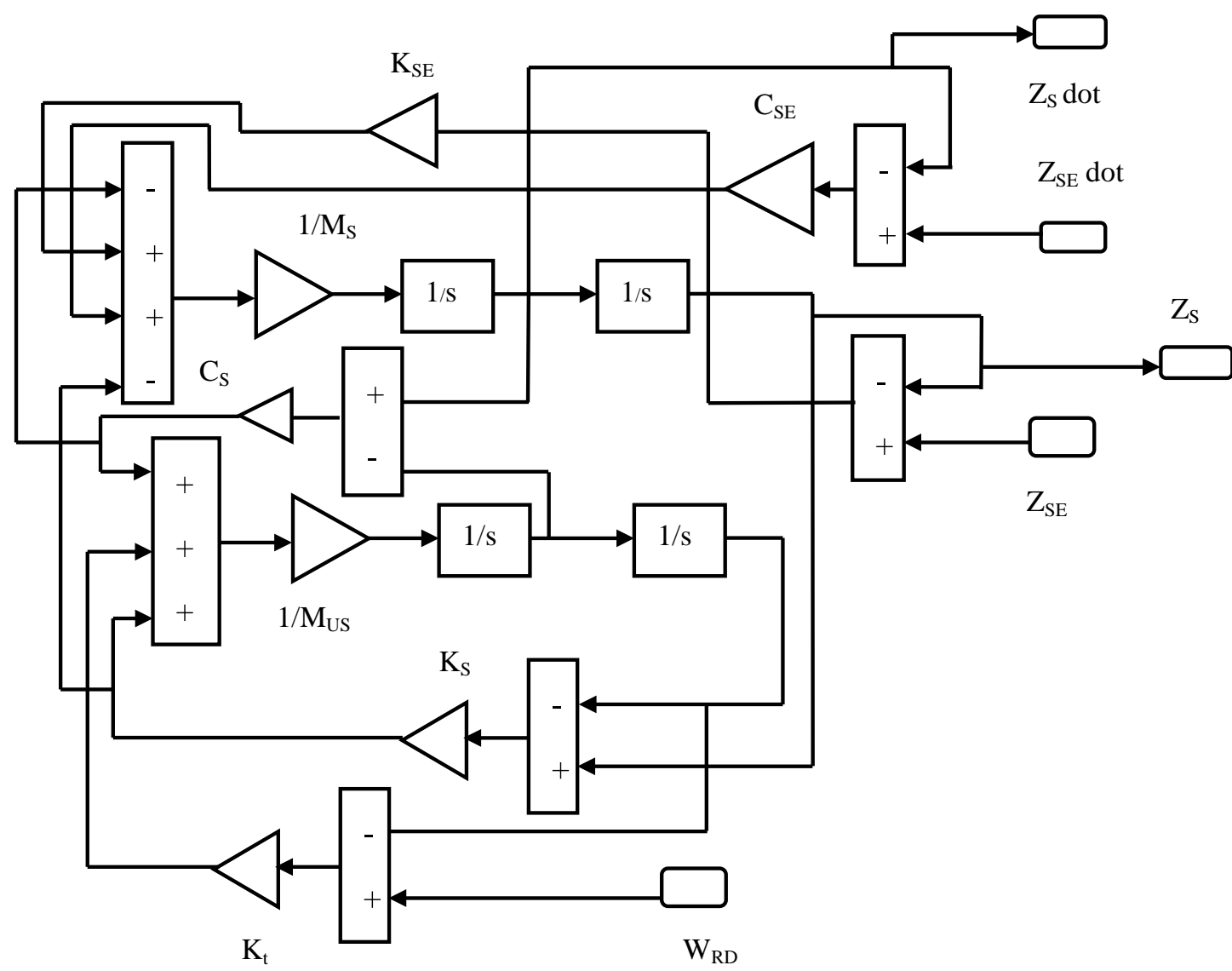

Figure 4 Passive suspension structure.

The semi-active suspension differs from passive suspension as it consists of an MR damper or shock absorber commonly known as an MR damper. This damper has a unique property that the damping coefficient of its viscous fluid can be varied. The MR damper consists of electric coils surrounding the MR viscous fluid. Its damping can be varied by changing the magnetic field of the coil surrounding the viscous fluid. Generally, the vehicle's sprung mass displacement or its acceleration is taken as feedback of the system and is fed to the controller. The controller compares the signal with a reference value; the reference value is taken as zero as, overshoot of suspension is required to be kept minimum. The 
http://wjst.wu.ac.th

controller sends a voltage signal to the MR damper corresponding to the error signal. The voltage range for most of the MR damper is in the range of 0 to 3 volts. The damping of the MR damper changes in response to the voltage supplied to it as an output of the controller. The semi-active system is a closedloop system where feedback of the vehicle's response against road undulation is fed back to the system for changing the damping coefficient, therefore improving the ride performance of the vehicle. In this work simulation model of semi-active suspension with PID controller and BELBIC controller is prepared.

The controller's model is prepared in the Matlab/Simulink environment for simulation. For the proposed model of BELBIC semi-active suspension the sensory input $\left(\mathrm{I}_{\mathrm{SI}}\right)$, emotional signal, or reward $\left(\mathrm{I}_{\mathrm{ES}}\right)$ and learning rates of the system are given by Eqs. (25) - (28). Here, $\mathrm{E}_{\mathrm{r}}$ is the error signal and $\mathrm{K}_{\mathrm{E} 1}$, and $\mathrm{K}_{\mathrm{E} 2}$ are gaining for emotional signal and orbitofrontal cortex, respectively [17].

$\mathrm{I}_{\mathrm{SI}}=\int E_{r}$

$\mathrm{I}_{\mathrm{ES}}=K_{E 1} \int E_{r}$

$\alpha_{b e}=K_{E 2}\left|E_{r}\right|$

$\beta_{b e}=10 \alpha_{b e}$

$\mathrm{E}_{\mathrm{r}}=$ Error signal

$\mathrm{K}_{\mathrm{E} 1}$ and $\mathrm{K}_{\mathrm{E} 2}=$ Gains for emotional signal and orbitofrontal cortex

Figure 5 shows the internal configuration of the orbitofrontal cortex of the proposed BELBIC controller in the Matlab/Simulink environment.

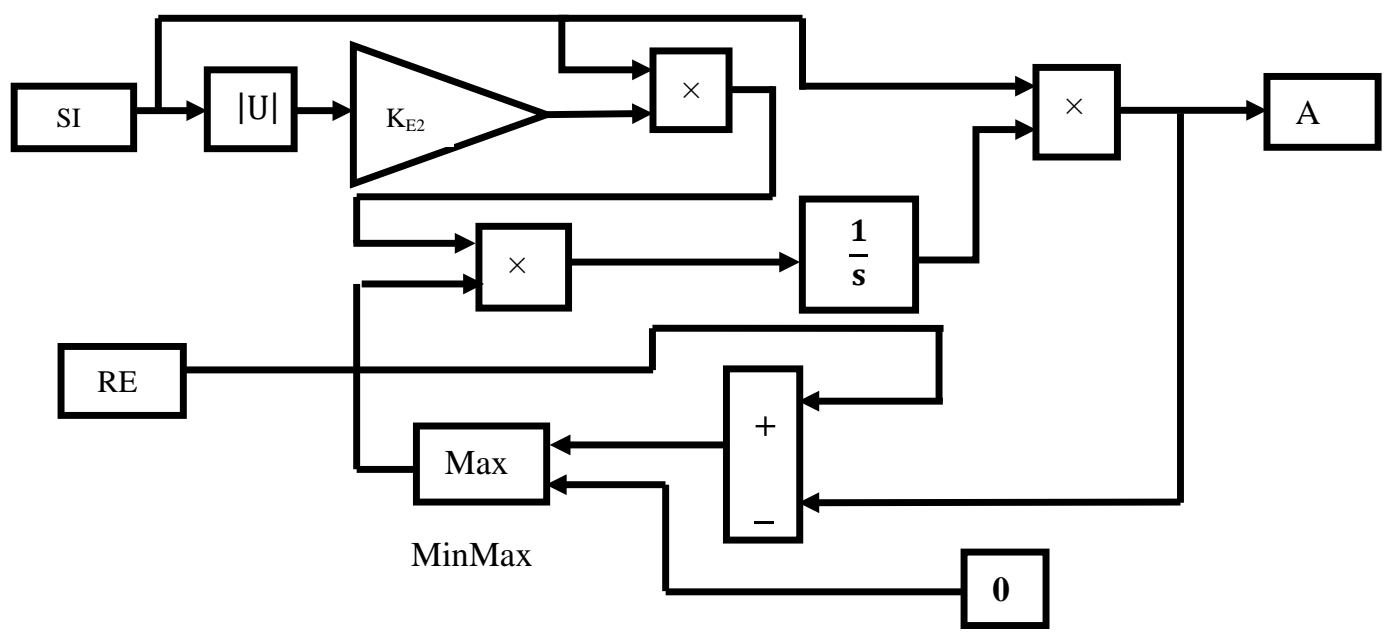

Figure 5 Orbitofrontal cortex structure.

The internal structure of sensory input of BELBIC controller constructed in Simulink window is shown in Figure 6. 


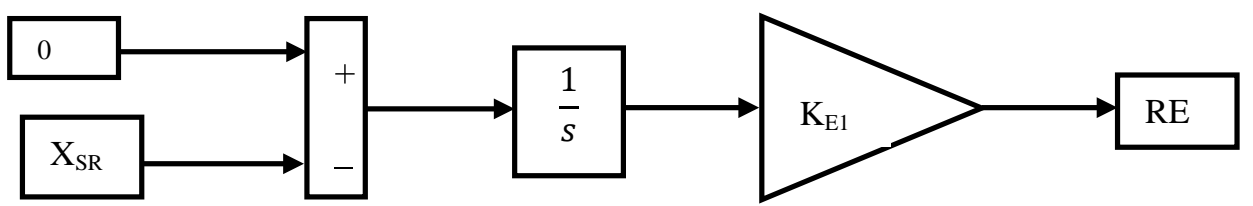

Figure 6 Simulink structure of the emotional signal.

The semi-active suspension with the PID controller in this work receives sprung mass displacement as a feedback signal. The PID controller analyses the error signal, which is the difference between the reference value or set value and the feedback signal. Corresponding to the error signal PID controller generates a voltage signal as an output based onEq. (19), which is fed to the MR damper. The Simulink structure of the PID controller is shown in Figure 7. The Simulink structure of semi-active suspension with the controller is shown in Figure 8. The Simulink structure prepared by interlinking of sprung, unsprung mass, MR damper, and controller based on Eqs. (11) and (12). The controller block in the figure can be replaced with the type of controller used for the system e.g. PID, Fuzzy, BELBIC, etc. The whole model can be prepared by interlinking Eqs. (7) - (12).

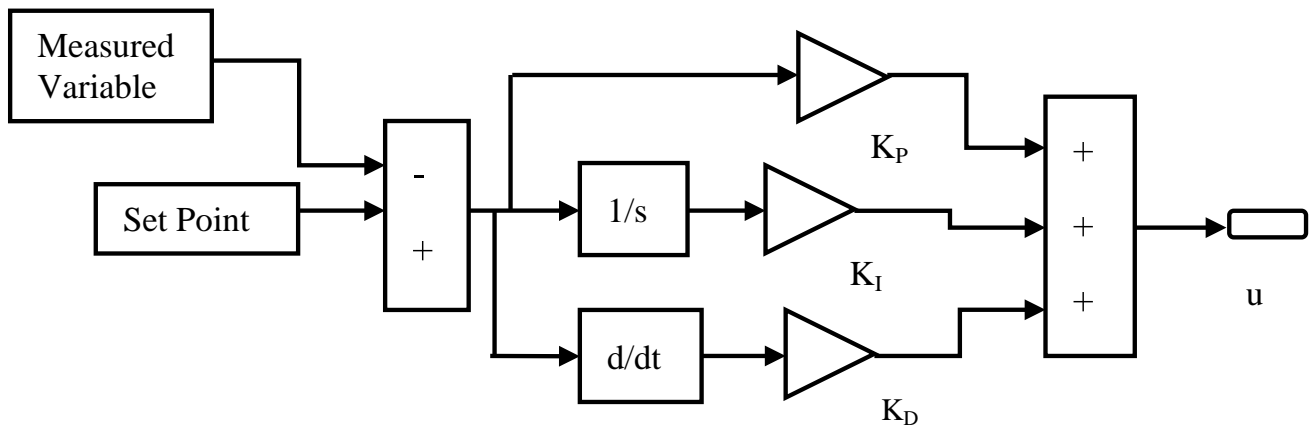

Figure 7 Structure of PID controller.

The input simulation parameters to the model are given as per Table 2. The model is simulated to analyze the human's body vibration response and also of vehicle.

Table 2 Model input parameter values.

\begin{tabular}{|c|c|c|}
\hline S. No & Parameter & Value \\
\hline 1. & Sprung Mass, $\mathrm{M}_{\mathrm{SR}}$ & $250 \mathrm{Kg}$ \\
\hline 2. & Unsprung Mass, $\mathrm{M}_{\mathrm{US}}$ & $35 \mathrm{Kg}$ \\
\hline 3. & Tire Stiffness, $\mathrm{K}_{\mathrm{TR}}$ & $160000 \mathrm{~N} / \mathrm{m}$ \\
\hline 4. & Bump Height, $\mathrm{W}_{\mathrm{RD}}$ & $10 \mathrm{~cm}$ \\
\hline 5. & Suspension Spring Stiffness, $\mathrm{K}_{\mathrm{SR}}$ & $16000 \mathrm{~N} / \mathrm{m}$ \\
\hline 6. & Suspension Damping, $\mathrm{C}_{\mathrm{SR}}$ & $980 \mathrm{~N}-\mathrm{s} / \mathrm{m}$ \\
\hline 7. & Mass Buttock \& Legs, $\mathrm{M}_{\mathrm{BL}}$ & $20 \mathrm{Kg}$ \\
\hline 8. & Buttock \& Legs Stiffness, $K_{\mathrm{BL}}$ & $40000 \mathrm{~N} / \mathrm{m}$ \\
\hline 9. & Buttock \& Legs Damping, $\mathrm{C}_{\mathrm{BL}}$ & $2500 \mathrm{~N}-\mathrm{s} / \mathrm{m}$ \\
\hline 10. & Head Mass, $\mathrm{M}_{\mathrm{HE}}$ & $5 \mathrm{Kg}$ \\
\hline
\end{tabular}




\begin{tabular}{cll}
\hline S. No & Parameter & Value \\
\hline 11. & Head Stiffness, $\mathrm{K}_{\mathrm{HE}}$ & $130000 \mathrm{~N} / \mathrm{m}$ \\
12. & Head Damping, $\mathrm{C}_{\mathrm{HE}}$ & $250 \mathrm{~N}-\mathrm{s} / \mathrm{m}$ \\
13. & Body Mass, M $\mathrm{BO}_{\mathrm{BO}}$ & $40 \mathrm{Kg}$ \\
14. & Body Stiffness, $\mathrm{K}_{\mathrm{BO}}$ & $3500 \mathrm{~N} / \mathrm{m}$ \\
15. & Body Damping, $\mathrm{C}_{\mathrm{BO}}$ & $750 \mathrm{~N}-\mathrm{s} / \mathrm{m}$ \\
16. & Seat Mass, $\mathrm{M}_{\mathrm{SE}}$ & $35 \mathrm{Kg}$ \\
17. & Seat Stiffness, $\mathrm{K}_{\mathrm{SE}}$ & $7000 \mathrm{~N} / \mathrm{m}$ \\
18. & Seat Damping, $\mathrm{C}_{\mathrm{SE}}$ & $900 \mathrm{~N}-\mathrm{s} / \mathrm{m}$ \\
\hline
\end{tabular}

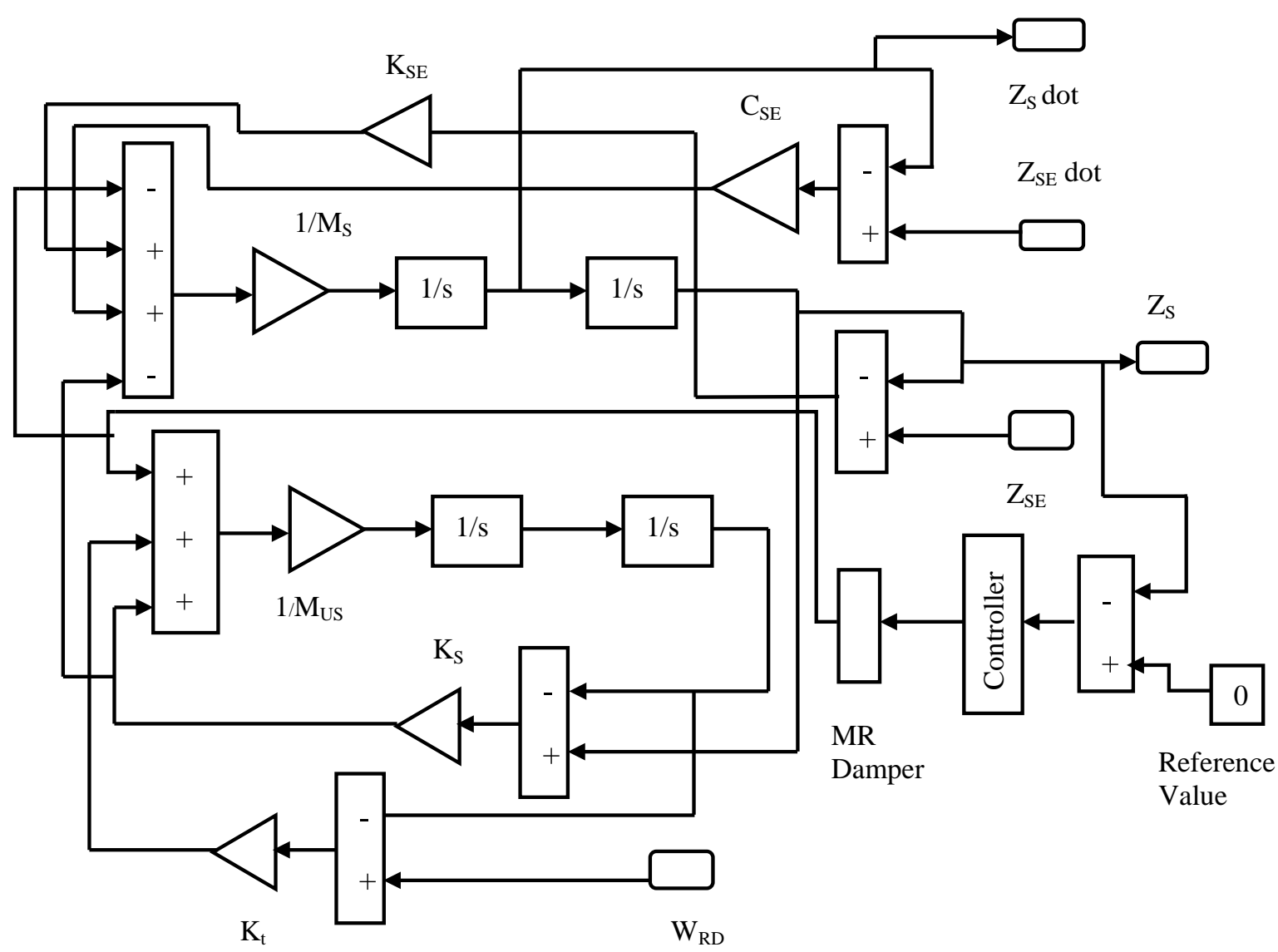

Figure 8 Structure of semi-active suspension

\section{Road bump}

The input to the proposed model of car was modeled as a circular and trapezoidal speed bump as per specification given by Indian Road Congress (IRC). The height of the profile for the circular bump is 0.1 $\mathrm{m}$ and the width of the bump is $3.5 \mathrm{~m}$ [30]. The mathematical expression given by Eq. (29) is used for the bump and is shown in Figure 9.

$W_{R}=\left(\frac{0.10}{2}\right)(1-\cos (\omega t))$

where vehicle velocity is $\mathrm{V}$ and exciting frequency $\omega$ is given as $2 \pi \mathrm{V} / 3.5$. 
http://wjst.wu.ac.th

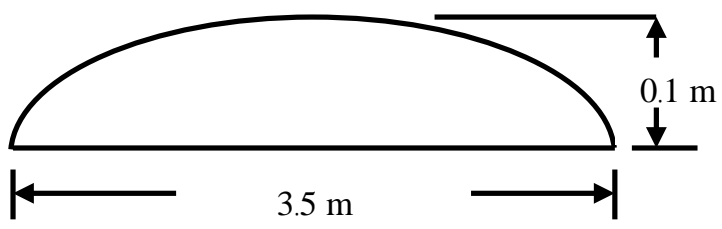

Figure 9 Circular speed bump.

The trapezoidal bump is expressed by the Eqs. (30) - (33). The standard height as per IRC specification is $0.1 \mathrm{~m}$, whereas slant height horizontal span is $0.6 \mathrm{~m}$, the flat top of the bump has a span of $2.5 \mathrm{~m}$. The configuration of the trapezoidal bump is shown in Figure 10.

$\mathrm{x} \leq 0, \mathrm{y}=0$

$0 \leq \mathrm{x} \leq 0.6, \mathrm{y}=0.167 \mathrm{x}$

$0.6 \leq x \leq 3.1, y=0.1$

$3.1 \leq \mathrm{x} \leq 3.7, \mathrm{y}=((-0.167 \mathrm{x})+0.6179)$

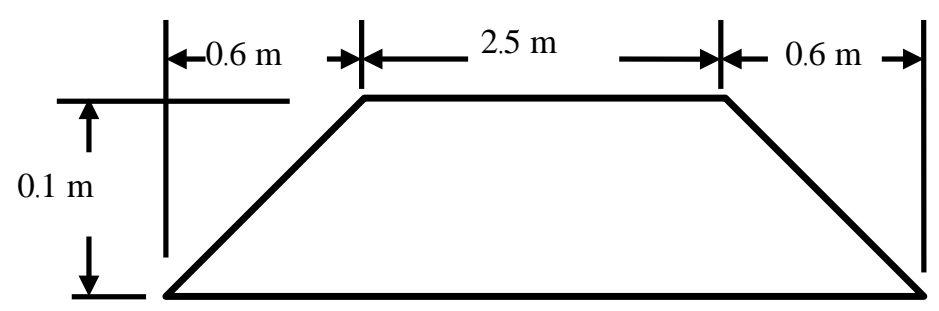

Figure 10 Trapezoidal speed bump.

\section{Simulation}

The simulation model for passive, PID, and BEL controlled suspension is simulated in Matlab/Simulink environment.Two types of speed bump IRC configuration i.e. circular and trapezoidal are used as input to the system. The gains for the proposed controller based on emotional learning of the brain are calculated by trial and error method and for PID controller by tuning in Simulink. The results for bounce or displacement of different body parts and sprung mass of the vehicle is analyzed and compared for percentage improvement in comparison to passive and PID suspension. The response for a circular speed bump and trapezoidal bumps are represented in Figures 11(a) - 11(j).

Figure 11(a) shows the comparative response of head displacement for passive; PID and BELBIC controlled systems when the vehicle passes through the circular bump. The response shows significant improvement by intelligent BEL controlled system, which will improve ride quality. The overshoot is $0.1138 \mathrm{~m}$ for PID and $0.1247 \mathrm{~m}$ for passive one. The overshoot for PID is decreased in comparison to passive suspension and follows the pattern obtained by Bashir et al. [1] and Upadhyaya and Gupta [2]. The overshoot of head displacement is coming out $0.1012 \mathrm{~m}$ for the BELBIC system and shows abetter result than the PID system. 


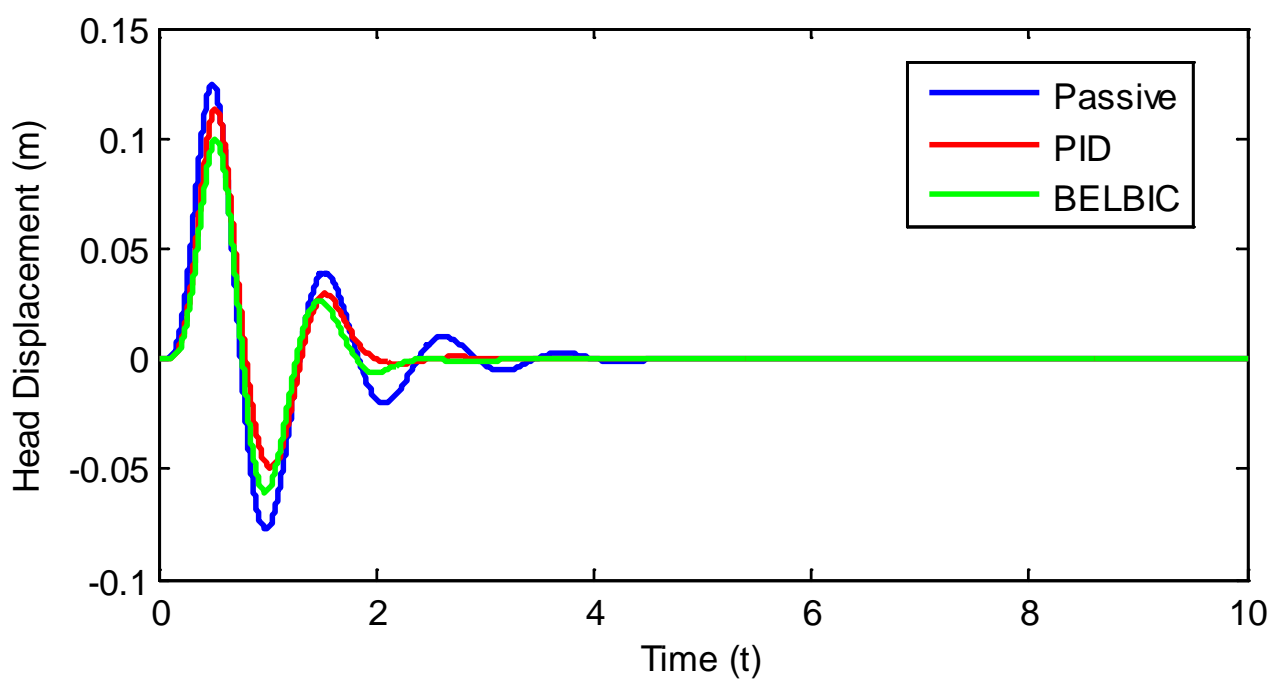

Figure 11(a) Head displacement (circular)

Figure 11(b) shows the comparison of head displacement for passive, PID, and BELBIC controlled systems when the vehicle passes through the trapezoidal bump. The displacement overshoot for passive comes as $0.1763 \mathrm{~m}$ whereas $0.1574 \mathrm{~m}$ for PID which follows the trend similar to the work performed by Youness and Lobusov [10]. The BELBIC controlled system gives an overshoot of $0.1414 \mathrm{~m}$, thus giving the best out of 3 systems.

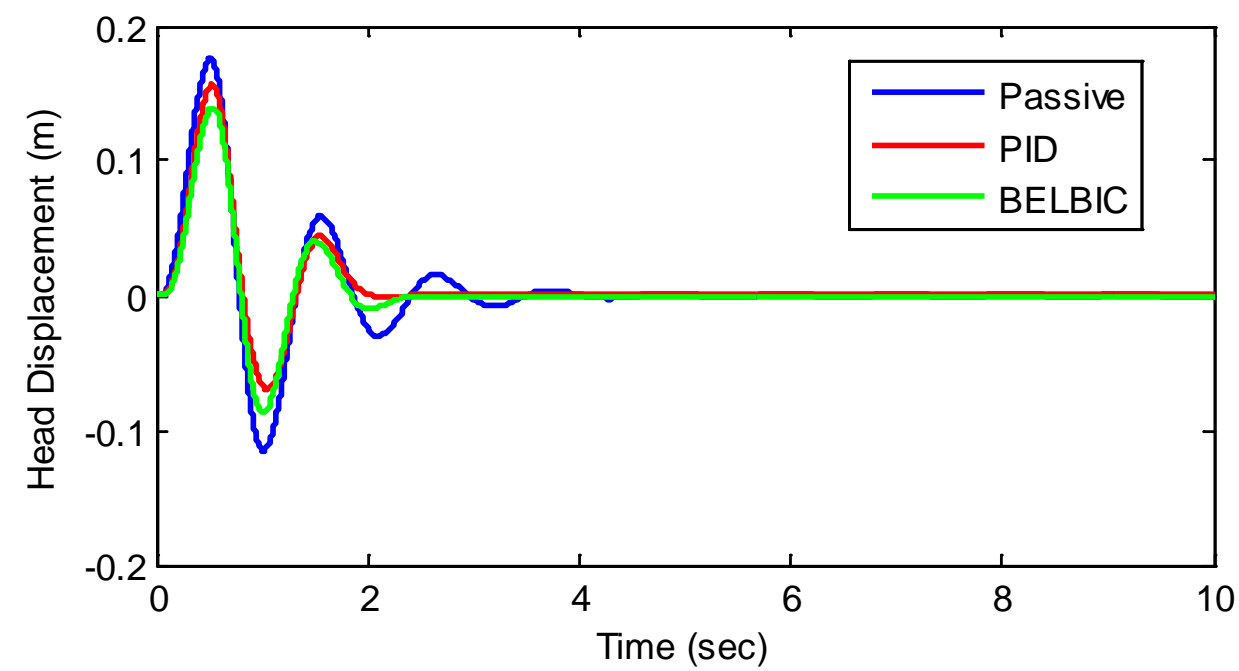

Figure 11(b) Head displacement (trapezoidal)

Figures 11(c) and 11(d) show body displacement against circular and trapezoidal bumps, respectively. The overshoot is $0.1200 \mathrm{~m}$ for PID and $0.1312 \mathrm{~m}$ for passive, respectively in the case of circular bump and similar results have been reported in the work of Dutta and Prakash [12]. The result of the proposed BELBIC has been reduced in comparison to passive and PID and comes out to be $0.1065 \mathrm{~m}$. 
For trapezoidal, overshoot comes out 0.1809, 0.1622, and $0.1454 \mathrm{~m}$ for passive, PID, and BELBIC systems, respectively.

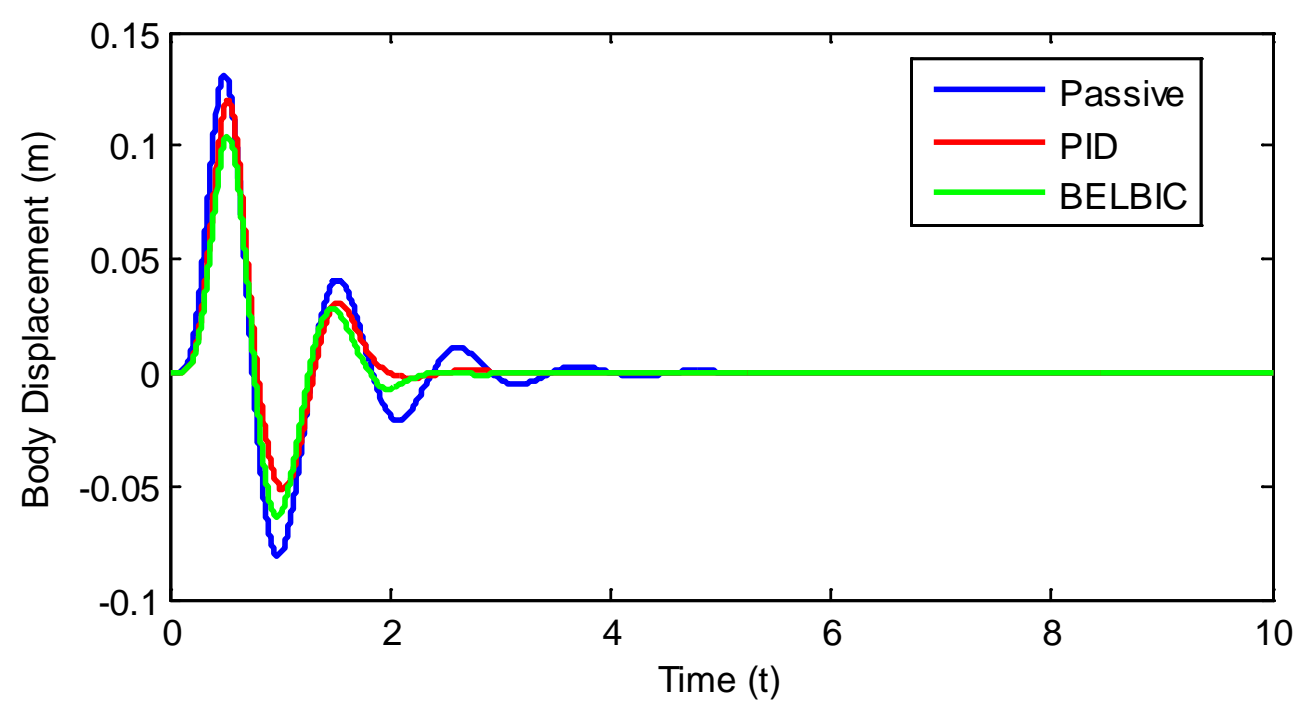

Figure 11(c) Body displacement (circular)

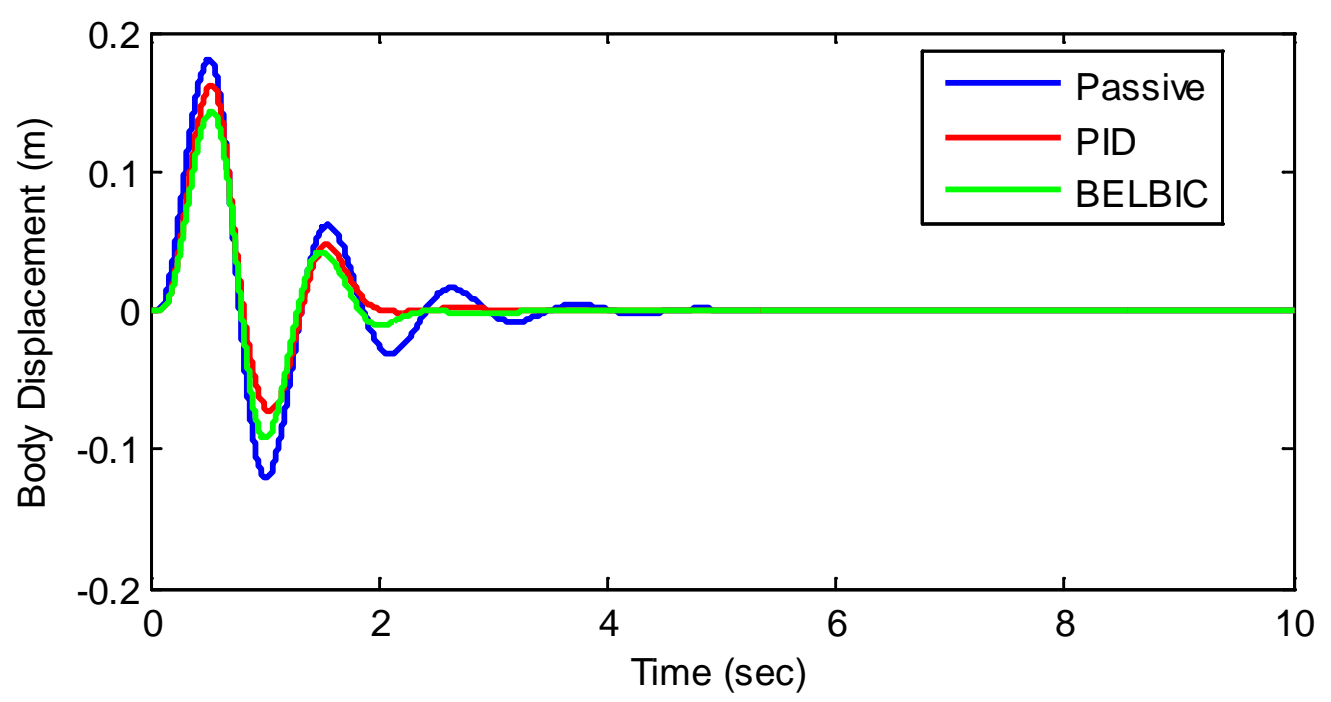

Figure 11(d) Body displacement (trapezoidal) 
Figures 11(e) and 11(f) show buttock and leg displacement response. The intelligent controller gives improved results and its overshoot comes out 0.1010 and $0.1412 \mathrm{~m}$ in comparison to 0.1136 and $0.1572 \mathrm{~m}$ for PID and the passive response of 0.1245 and $0.1761 \mathrm{~m}$ for circular and trapezoidal bump, respectively.

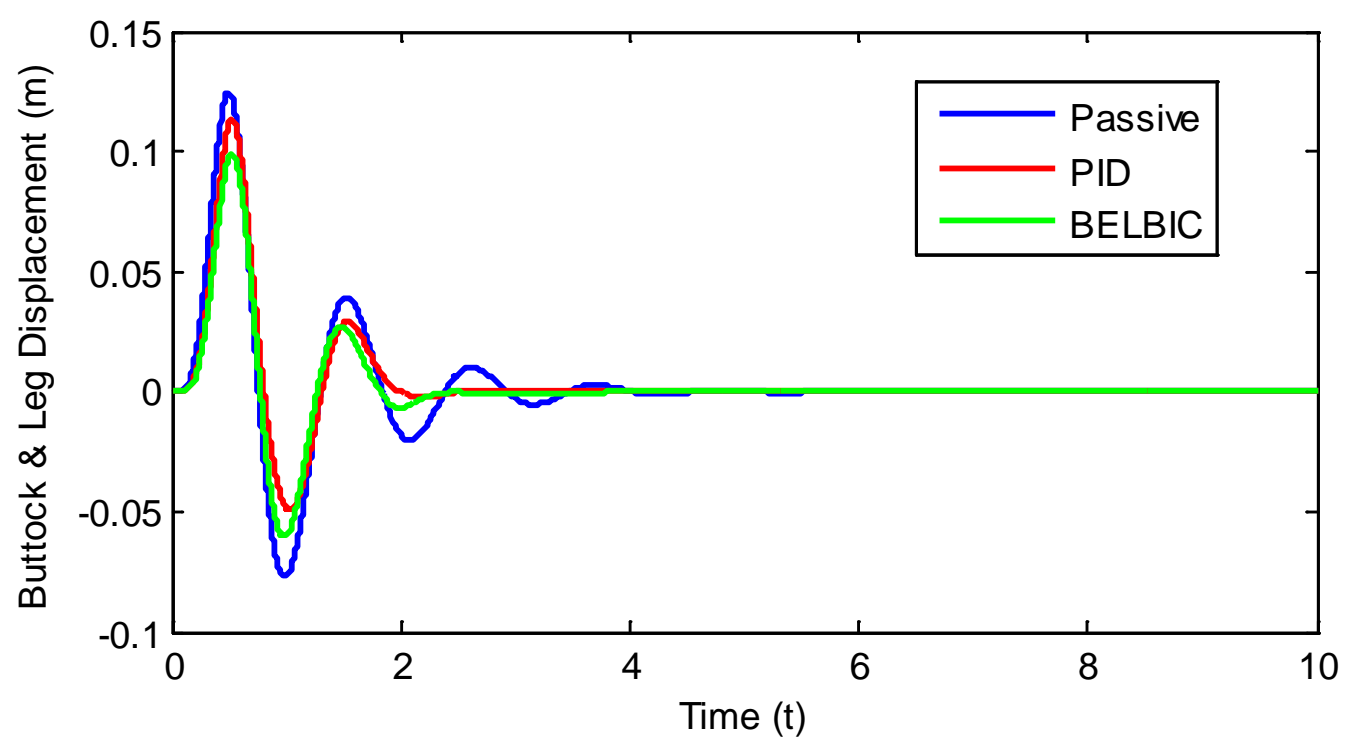

Figure 11(e) Buttock \& leg displacement (circular)

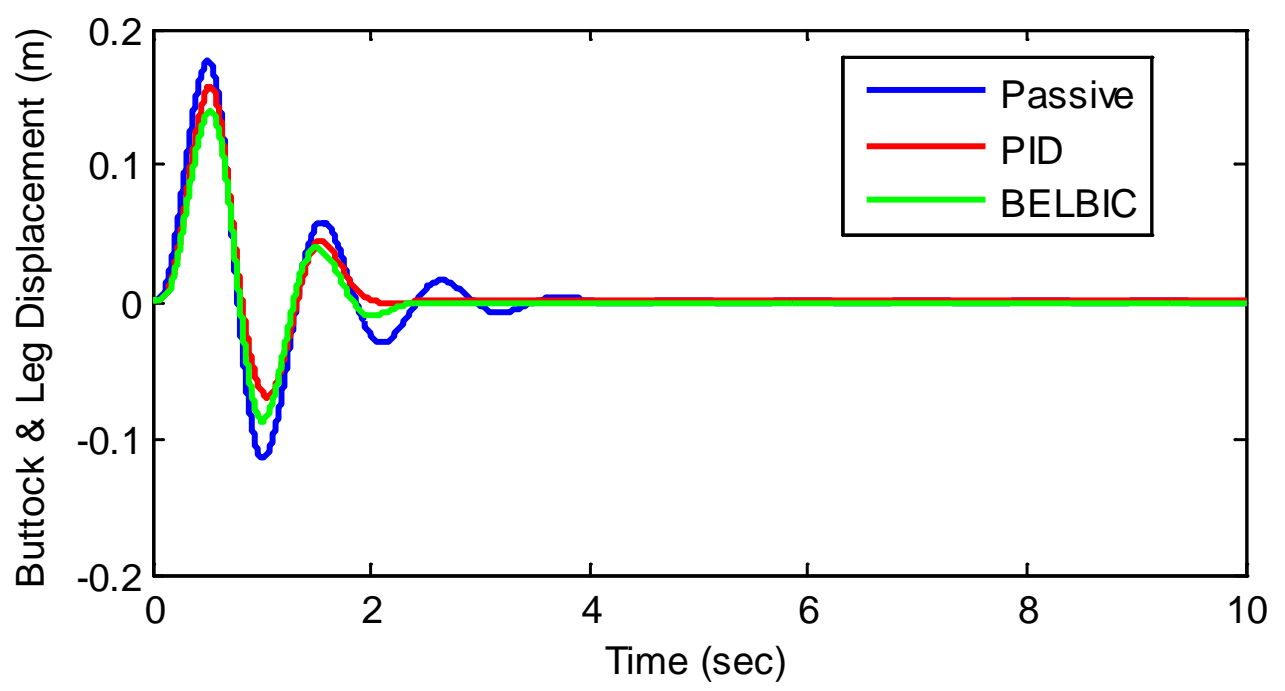

Figure 11(f) Buttock \& leg displacement (trapezoidal) 
http://wjst.wu.ac.th

Figure 11(g) for seat displacement comparison for circular bump response shows overshoot for passive $0.1185 \mathrm{~m}$ and reduced to $0.1080 \mathrm{~m}$ for PID and $0.0961 \mathrm{~m}$ for the BELBIC system.

Figure 11(h) shows BELBIC system response as $0.1368 \mathrm{~m}$ which is less than the overshoot of PID and passive system i.e. $0.1520 \mathrm{~m}, 0.1710 \mathrm{~m}$, respectively for the trapezoidal bump.

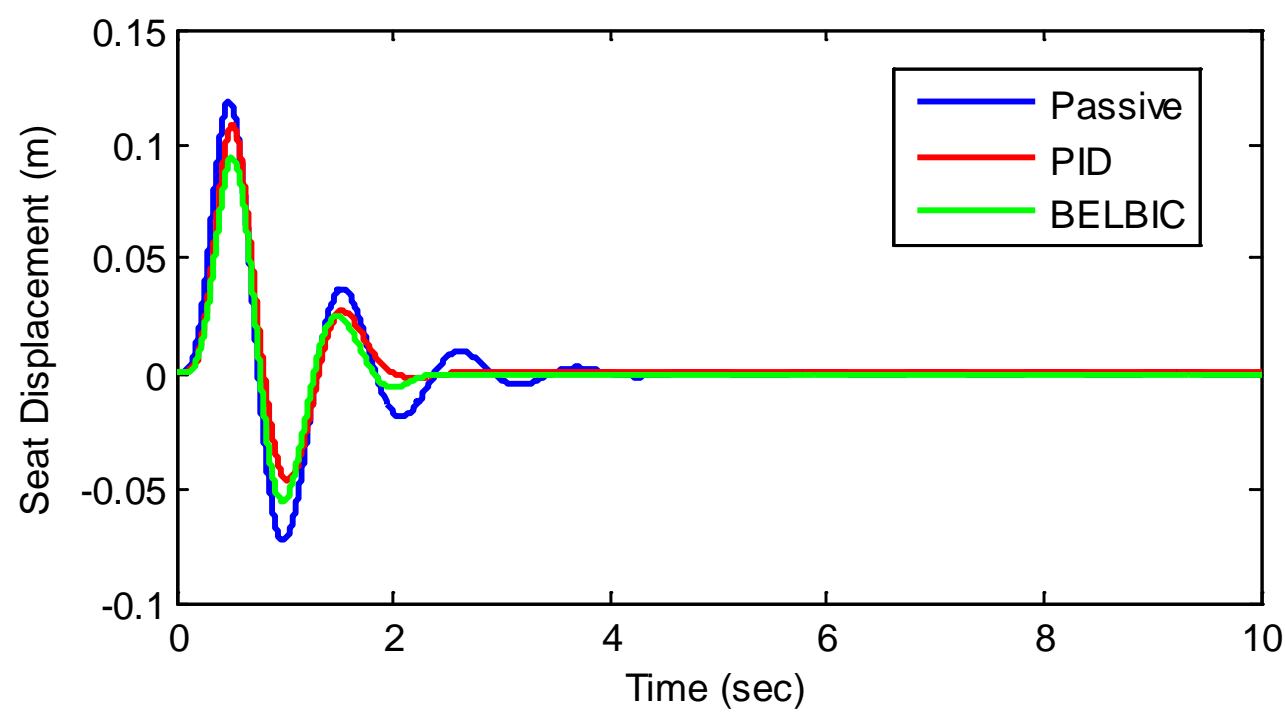

Figure 11(g) Seat displacement (circular)

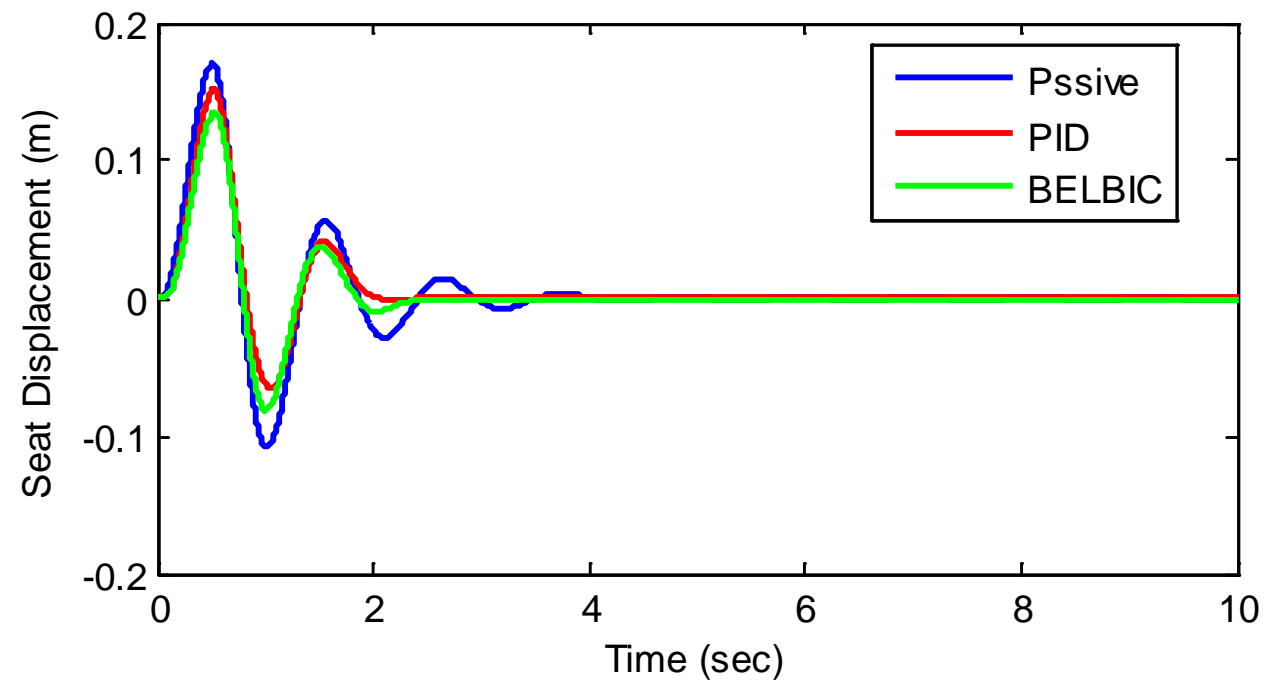

Figure 11(h) Seat displacement (trapezoidal) 
http://wjst.wu.ac.th

Figures 11(i) and 11(j) show the comparison of sprung mass displacement for the 3 systems against circular and trapezoidal bumps, respectively. The response against the circular profile comes out as 0.1064, 0.0907, and $0.0867 \mathrm{~m}$ for passive, PID, and intelligent BEL controller system. In the case of the trapezoidal speedbump, the overshoot for the BELBIC system is $0.1168 \mathrm{~m}$ and of PID and passive configuration is $0.1299,0.1469 \mathrm{~m}$, respectively. The response of the PID controlled system shows a reduction in overshot of the vehicle's sprung mass as well as in the driver's body part and conforms to the PID controlled system's pattern obtained in the work of Prashantkumar et al. [25], Ravi and Mija [26]. The proposed novel BELBIC controlled system shows much better improvement in response as compared to PID and passive system.

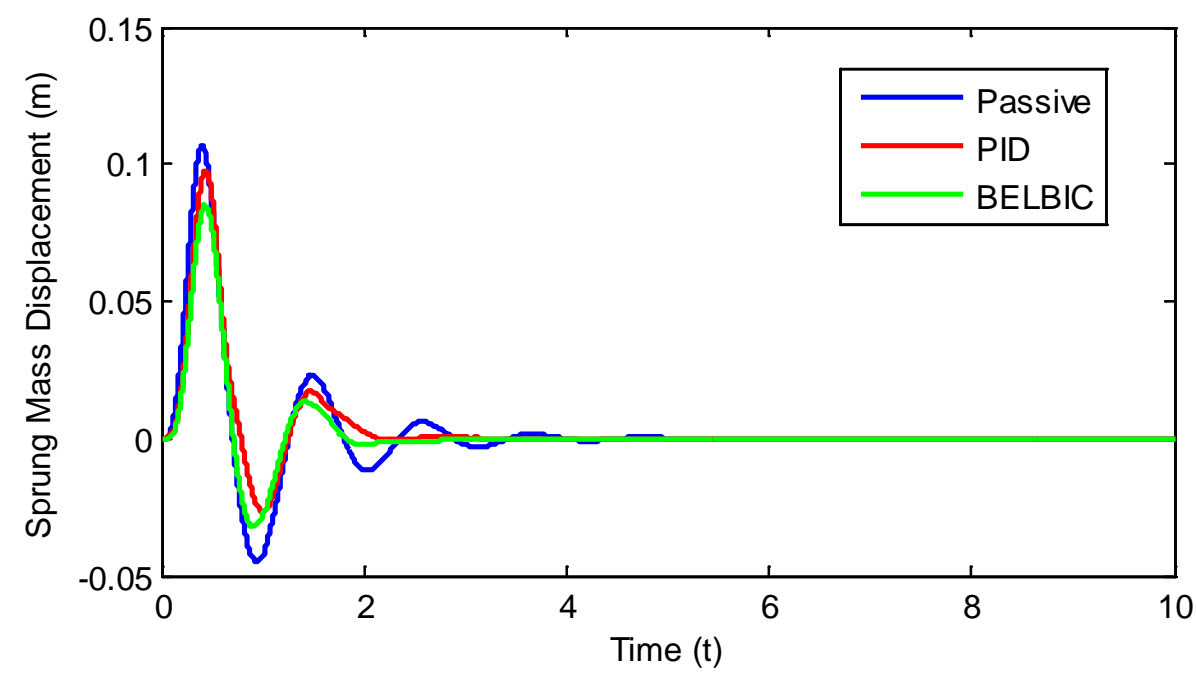

Figure 11(i) Sprung mass displacement (circular)

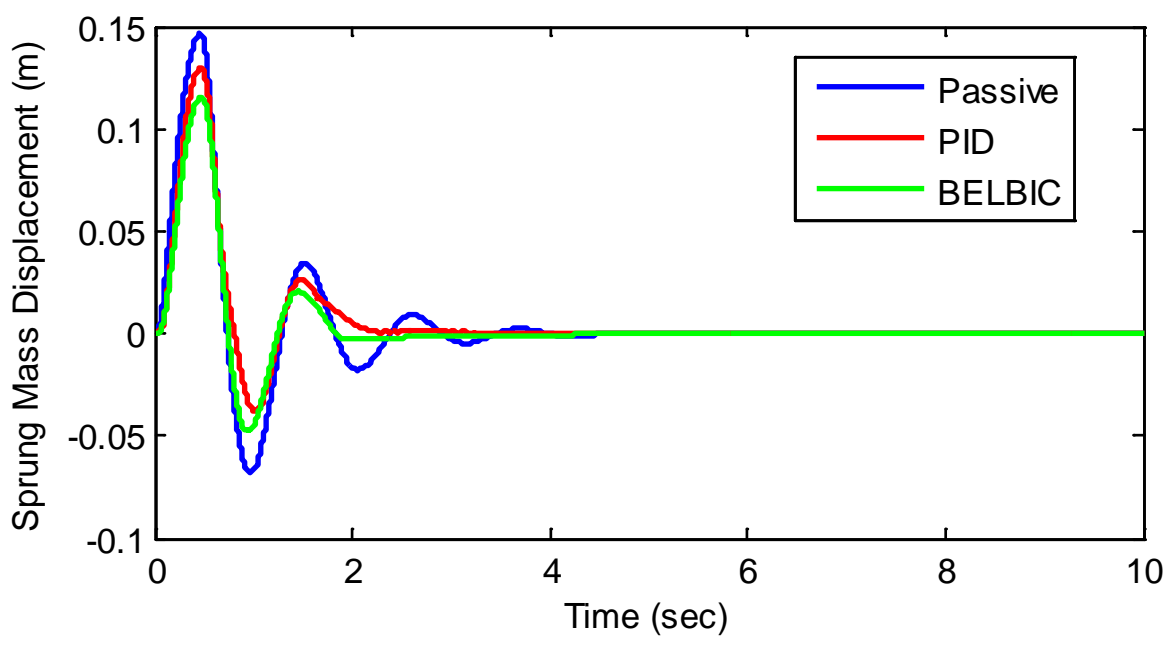

Figure 11(j) Sprung mass displacement (trapezoidal)

Figure 11 Bounce response of circular vs trapezoidal bump. 


\section{Result and discussion}

The analysis of responses of passive, PID, and BELBIC controlled system when compared, best improvement comes out in the performance of BEL controlled system. The overshoot for head, body, buttock and leg, seat and sprung mass for BELBIC are 0.1012, 0.1065, 0.1010, 0.0961 and $0.0867 \mathrm{~m}$ whereas 0.1138, 0.1200, 0.1136, 0.1080 and $0.0907 \mathrm{~m}$ for PID and 0.1247, 0.1312, 0.1245, 0.1185 and $0.1064 \mathrm{~m}$ for passive configuration against circular bump. Overshoot response of BELBIC system is $0.1414,0.1454,0.1412,0.1368$ and $0.1168 \mathrm{~m}$ for trapezoidal bump whereas $0.1574,0.1622,0.1572$, 0.1520 and $0.1299 \mathrm{~m}$ for PID and $0.1763,0.1809,0.1761,0.1710$ and $0.1464 \mathrm{~m}$ for passive system against trapezoidal profile. The response of PID controlled suspension is better than passive as it shows a reduction in overshoot against circular and trapezoidal bumps. This result follows the pattern of work done by Amiruddin et al. [18] and Emam [24]. The proposed BELBIC controlled system shows a maximum reduction in overshoot and gives the best performance. The comparative analysis of displacement overshoot response is shown in tabulated form in Tables $\mathbf{3}$ and $\mathbf{4}$. A better understanding of improvement in ride quality can be understood by percentage reduction of overshoot response of different body parts of passenger, therefore is tabulated in Table 5. The analysis of percentage reduction shows an improvement of approximately 18 and $10 \%$ for BELBIC and PID system against circular profile, compared to passive and of approximately 20,11\% for BELBIC and PID, respectively for the trapezoidal profile.The result shows that the newly proposed approach of brain's emotional learning for controller shows significant scope for future work in automotive control design.

Table 3 Displacement response for circular bump.

\begin{tabular}{lcccccc}
\hline & \multicolumn{3}{c}{ Human body parts } & & \multicolumn{2}{c}{ Vehicle parts } \\
\cline { 2 - 3 } \cline { 6 - 7 } Suspension Type & Head & \multicolumn{1}{c}{ Body } & Buttock \& Leg & & Seat & \multicolumn{2}{c}{ Sprung Mass } \\
& $\mathbf{X}_{\mathbf{H E}}(\mathbf{m})$ & $\mathbf{X}_{\mathbf{B O}}(\mathbf{m})$ & $\mathbf{X}_{\mathbf{B L}}(\mathbf{m})$ & & $\mathbf{X}_{\mathbf{S E}}(\mathbf{m})$ & $\mathbf{X}_{\mathbf{S R}}(\mathbf{m})$ \\
\hline Passive & 0.1247 & 0.1312 & 0.1245 & & 0.1185 & 0.1064 \\
PID controlled & 0.1138 & 0.1200 & 0.1136 & & 0.1080 & 0.0907 \\
BELBIC controlled & 0.1012 & 0.1065 & 0.1010 & & 0.0961 & 0.0867 \\
\hline
\end{tabular}

Table 4 Displacement response for trapezoidal bump.

\begin{tabular}{lcccccc}
\hline & \multicolumn{3}{c}{ Human body parts } & & \multicolumn{2}{c}{ Vehicle parts } \\
\cline { 2 - 3 } \cline { 7 - 8 } Suspension Type & Head & \multicolumn{1}{c}{ Body } & Buttock \& Leg & & Seat & \multicolumn{2}{c}{ Sprung Mass } \\
& $\mathbf{X}_{\mathbf{H E}}(\mathbf{m})$ & $\mathbf{X}_{\mathbf{B O}}(\mathbf{m})$ & $\mathbf{X}_{\mathbf{B L}}(\mathbf{m})$ & & $\mathbf{X}_{\text {SE }}(\mathbf{m})$ & $\mathbf{X}_{\mathbf{S R}}(\mathbf{m})$ \\
\hline Passive & 0.1763 & 0.1809 & 0.1761 & & 0.1710 & 0.1469 \\
PID controlled & 0.1574 & 0.1622 & 0.1572 & & 0.1520 & 0.1299 \\
BELBIC controlled & 0.1414 & 0.1454 & 0.1412 & & 0.1368 & 0.1168 \\
\hline
\end{tabular}

Table 5 Percentage overshoot reduction response.

\begin{tabular}{|c|c|c|c|c|c|c|}
\hline \multirow[b]{2}{*}{ Suspension Type } & \multirow[b]{2}{*}{ Speed bump } & \multicolumn{3}{|c|}{ Human body parts } & \multicolumn{2}{|c|}{ Vehicle parts } \\
\hline & & $\begin{array}{c}\text { Head } \\
(\%)\end{array}$ & $\begin{array}{l}\text { Body } \\
\text { (\%) }\end{array}$ & $\begin{array}{c}\text { Buttock \& Leg } \\
\text { (\%) }\end{array}$ & $\begin{array}{l}\text { Seat } \\
(\%)\end{array}$ & $\begin{array}{c}\text { Sprung Mass } \\
(\%)\end{array}$ \\
\hline PID controlled & Circular & 8.74 & 8.53 & 8.75 & 11.11 & 14.75 \\
\hline BELBIC controlled & Circular & 18.84 & 18.82 & 18.87 & 18.90 & 18.51 \\
\hline PID controlled & Trapezoidal & 10.72 & 10.33 & 10.73 & 11.11 & 11.57 \\
\hline BELBIC controlled & Trapezoidal & 19.79 & 19.62 & 19.81 & 20.00 & 20.49 \\
\hline
\end{tabular}


http://wjst.wu.ac.th

\section{Conclusions}

The results of simulation work performed with newly proposed BELBIC controlled semi-active suspension shows significant improvement in ride quality. The performance is compared with a 6DOF passive and PID controlled semi-active model of a car with a passenger. The impact of the controller on the human body is also analyzed and shows improvement. The response is analyzed against 2 types of speed bump i.e. circular and trapezoidal. The following concluding observations are obtained:

The PID controlled semi-active suspension performed better in comparison to passive suspension as overshoot is reduced for the PID system. The reduction against the circular bump is 11.11 and $14.75 \%$ for the vehicle seat and sprung mass, respectively. The human body parts also show a reduction in their overshoot. The percentage reduction for head, body, buttock, and leg are 8.74, 8.53 and $8.75 \%$, respectively. Similar results were obtained in the work of Emam [24], Mihai and F Andronic [27].

The response of the PID controlled system against trapezoidal bump is also better. The vehicle parts i.e. seat and sprung mass show a reduction of 11.11, $11.57 \%$ in overshoot. The head, body, buttock, and leg of the human model show a reduction of $10.72,10.33$, and $10.73 \%$, respectively. The response of the PID system is following the trend of response obtained in the work of Dutta and Prakash [12], Amiruddin et al. [18].

The BELBIC controlled semi-active shows a reduction of 18.84and $18.82 \%$ in overshoot for the vehicle seat and sprung mass while passing through the circular bump. The overshoot is also reduced for the human head, body, buttock, and leg by 18.84, 18.82 and $18.87 \%$, respectively.

The BELBIC controlled semi-active suspension performance against trapezoidal bump also comes out excellent. The overshoot reduction for sprung mass and seat are 20.49 and $20 \%$, respectively. The reduction for head, body, buttock, and leg for the lumped human model are 19.79, 19.62and $19.81 \%$, respectively.

The proposed BELBIC controlled suspension has completely outperformed PID controlled suspension as well as passive suspension, thus ensuring much better ride quality and ride comfort. The improvement in vibration effect on body parts shows that suspension system equipped with BELBIC controller will have a less severe effect on the fatigue of the body parts and allow the passenger to go for a long ride.

The BELBIC controller is very flexible in nature as its sensory input and emotional signal structure can be modeled as per the need for the problem. The structure can be modified by changing the mathematical expression of these two. It is also very fast in response due to its auto-learning ability which also makes it an intelligent controller. The controller is also suitable for multi-objective problems. Unlike the fuzzy controller where the designer needs to have a very vast knowledge of system behavior for designing the fuzzy rules and membership function; BELBIC needs the knowledge of mathematical expressions to define the structure of the controller. These features make BELBIC very effective and suitable for real-time control systems as it gives a quick response to the system. The major drawback of BELBIC is that there is no method to select its gains, and are adjusted by trial and error method. The proposed controller shows a huge scope for its use in different fields with the system having high uncertainty and non-linearity.The future work can be based on finding the gains of a controller using optimization techniques and also analyzing the performance of suspension system with hybridization of BELBIC controller with other types of conventional controller for performance improvement.

\section{References}

[1] AO Bashir, X Rui and J Zhang. Ride comfort improvement of a semi-active vehicle suspension based on hybrid fuzzy and fuzzy-PID controller. Stud. Inform. Control. 2019; 28, 421-30.

[2] S Upadhyaya and A Gupta. Hybrid robust control approach to enhance the functioning of semiactive suspension system. Int. Adv. Res. J. Sci. Eng. Technol. 2019; 6, 44-51.

[3] G Pohit. Vibration control of a car suspension system using a magnetorheological damper with fuzzy logic controller. In: Proceedings of the International Academic Conference, Rome, Italy. 2019, p. 146-50. 
http://wjst.wu.ac.th

[4] R Keramat, MH Ershadi and S Shojaeian. A comparison of fuzzy and brain emotional learningbased intelligent control approaches for a full bridge dc-dc converter. Int. J. Ind. Electron. Control Optim. 2019; 3, 197-206.

[5] M Jafari, V Sarfi, AGhasemkhani, H Livani, L Yang and H Xu. Adaptive intelligent secondary control of microgrids using a biologically-inspired reinforcement learning.In: Proceedings of the IEEE International conference on Power \& Energy Society General Meeting, Atlanta, USA. 2019, p. $1-5$.

[6] S Vanapalli and MV Rao. Emotional intelligent controller applied to unified power quality conditioner. Int. J. Recent Technol. Eng. 2019; 7, 295-300.

[7] K Saeed, ZSM Hashem, KM Reza, S Sajjad and E Selcuk. Robust model-free control of a class of uncertain nonlinear systems using BELBIC: Stability analysis and experimental validation. J. Braz. Soc. Mech. Sci. Eng. 2019; 41,1-12.

[8] P Ramesh and N Yadaiah. Data based reward formulation of BELBIC for DC motor position control. In: Proceedings of the IEEE Region 10 Conference TENCON, Kochi, India. 2019, p. 874-9.

[9] MB Cesar, JP Coelho and J Goncalves. Semi-active vibration control of a non-collocated civil structure using evolutionary-based BELTIC. Actuators 2019; 8, 1-19.

[10] SF Youness and EC Lobusov. Networked control for active suspension system. Procedia Comput. Sci. 2019; 150, 123-30.

[11] P Sharma and V Kumar. Design and analysis of a BELTIC controlled semi active suspension system. J. Phys. Conf. Ser. 2019; 1240, 1-9.

[12] A Dutta and S Prakash. Utilizing electric vehicles and renewable energy sources for load frequency control in deregulated power system using emotional controller. IETE J. Res. 2021. https://doi.org/10.1080/03772063.2019.1654936.

[13] S Kazima, M Jose and X Hui. Fuzzy logic controller for semi active suspension based on magnetorheological damper. Int. J. Automot. Eng. Technol. 2018; 7, 38-47.

[14] E Lofti and AA Rezaee. Generalized BELBIC. Neural Comput. Appl. 2019; 31, 4367-83.

[15] JM Sah, Z Taha and KA Ismail. Lightweight vehicle and driver's whole-body models for vibration analysis. IOP Conf. Ser. Mater. Sci. Eng. 2018; 318, 012069.

[16] IH Hong, JW Chung and CY Oh. A fusion control for a flexible manipulator using PID controller and BELBIC. J. Korean Soc. Mech. Technol. 2018; 20, 458-66.

[17] AAsarry, FM Naseer, TAZ Rahman, KAM Rezali and MZM Zain. Semi-active suspension control for formula SAE car using magneto-rheological fluid. In: Proceedings of the International Conference on Computer Applications and Industrial Electronics, Langkawi Island, Malaysia. 2017, p. 97-101.

[18] IM Amiruddin, M Pauziah, A Aminudin and MH Unuh. Design and development of the Macpherson Proton Preve Magneto rheological damper with PID Controller. IOP Conf. Ser. Mater. Sci. Eng. 2017; 248, 012003.

[19] S Senthilkumar, M Boopathi, TC Kanish and A Srivani. Fuzzy logic model for combined monitoring of weld strength and nugget hardness of friction stir weld. Walailak J. Sci. Tech. 2017; 14, 377- 88.

[20] W Chatlatanagulchai and T Benjalersyarnon. Closed loop input shaping with quantitative feedback controller applied to slewed two-staged pendulum. Walailak J. Sci. Tech. 2016; 13, 595-613.

[21] A Shahriar, KA Rahman and S Tanvir. Simulation and analysis of half-car passive suspension system. Mech. Eng. Res. J. 2016; 10, 66-70.

[22] CB Priya and N Gopalakrishnan. Parameter identification of long stroke and short stroke MR damper for itsuse in semi-active vibration control. J. Inst. Eng. India Ser. 2016; 97, 405-14.

[23] YZ Arslan. Experimental assessment of lumped parameter human body models exposed to whole body vibration. J. Mech. Med. Biol. 2015; 15, 1-13.

[24] AS Emam. Fuzzy self-tuning of pid controller for active suspension system. J. Adv. Powertrains Automot. 2015; 1, 34-41. 
http://wjst.wu.ac.th

[25] R Prashantkumar, SR Kulkarni, D Sharma, R Sambrani and VV Desai. Comparative analysis of multiple controllers for semi-active suspension system. In: Proceedings of the $2^{\text {nd }}$ International Conference on Emerging Research in Computing, Information, Communication and Applications, Bangalore, India. 2014, p. 595-606.

[26] R Ravi and SJ Mija. Design of brain emotional learning based intelligent controller (BELBIC) for uncertain systems. In: Proceedings of the IEEE International Conference on Advanced Communication Control and Computing Technologies, Ramanathapuram, India. 2014, p. 1089-93.

[27] I Mihai and F Andronic. Behavior of a semi-active suspension system versus a passive suspension system on an uneven road surface. Mechanika 2014; 20, 64-9.

[28] JW Kim and CY Oh. Control of a rotary inverted pendulum system using brain emotional learning based intelligent controller. J. Korean Soc. Manuf. Technol. Eng. 2013; 22, 837-44.

[29] H Metered, P Bonello and S Oyadiji. Nonparametric identification modeling of magnetorheological damper using chebyshev polynomials fits. SAE Int. J. Passeng. Cars Mech. Syst. 2009; 2, 1125-36.

[30] PSS Prasad and A Shirahatti. Investigation on effect of hump on a vehicle suspension for the comfortable ride. In: Proceedings of the National Conference on Emerging Trends in Mechanical Engineering, Bangalore, India. 2006, p. 1-6. 